\title{
SMART CITY STREET LIGHTING SYSTEM QUALITY AND CONTROL ISSUES TO INCREASE ENERGY EFFICIENCY AND SAFETY
}

\author{
ANSIS AVOTINS ${ }^{1 *}$, LESLIE ROBERT ADRIAN ${ }^{1,2}$, \\ RICARDS PORINS ${ }^{1}$, PETERIS APSE-APSITIS ${ }^{3}$, \\ LEONIDS RIBICKIS ${ }^{1}$ \\ ${ }^{1}$ Institute of Industrial Electronics and Electrical Engineering, \\ Riga Technical University, Riga, Latvia \\ ${ }^{2}$ Lesla Latvia Ltd, Riga, Latvia \\ ${ }^{3}$ Department of Industrial Electronics and Electrical Technologies, \\ Riga Technical University, Riga, Latvia
}

Received 9 February 2021; accepted 28 July 2021

\begin{abstract}
According to standards, the lighting system is one of the key elements to provide safety on city roads, defined by quality parameters. LED technology and movement detection sensor interaction bring about new regulation techniques, creating an energy-efficient smart LED lighting system concept. This paper reveals extensive comparative data analysis of Dialux simulation results before the project implementation phase and in-situ quality parameter measurements for various street profiles and LED luminary power types. After the project implementation phase, more than 1000 measurement points are
\end{abstract}

* Corresponding author. E-mail: ansis.avotins@rtu.lv

Ansis AVOTINS (ORCID ID 0000-0002-7639-5198)

Leslie Robert ADRIAN (ORCID ID 0000-0003-4663-276X)

Leonids RIBICKIS (ORCID ID 0000-0001-9077-1981)

Copyright (C) 2021 The Author(s). Published by RTU Press

This is an Open Access article distributed under the terms of the Creative Commons Attribution License (http://creativecommons.org/licenses/by/4.0/), which permits unrestricted use,

distribution, and reproduction in any medium, provided the original author and source are credited. 
reached. Further, energy efficiency increase issues in smart lighting systems are described in terms of LED luminary dimming profile analysis and future dynamic control application modes. The first findings clearly show that in most cases light output in simulation results is lower than in real situations; therefore, LED luminary power can be decreased, allowing for higher energy savings in first luminary maintenance years, keeping the same defined ME class or safety level. Let us suppose that the traffic intensity data are obtained from smart system sensors. In that case, the ME class can be dynamically selected during different night times, thus increasing safety and providing extra energy savings using the same system elements, as well as leading to better ROI values.

Keywords: energy efficiency, road safety, LED lighting systems, quality, smart city, intelligent control, in-situ measurements.

\section{Introduction}

Street lighting technology was created to increase safety on roads and decrease burglary during darkness hours of the day (incl., dusk, dawn and nighttime). When looking at traffic accidents or automobile fatalities, this statement is described in a journal article (AIEE, 1935) analysing data from various USA cities and revealing that without daylight, fatalities are 3-4 times higher than in normal lighting conditions, even traffic intensity decreases. Studies (Crabb \& Crinson, 2008) devoted to public roads of Great Britain also show that in nighttime less accidents happen than in daytime, and streets that have a lighting system still have more accidents than streets without it, but the severity ratio is much lower. In later years, street lighting systems became more prevalent in large and small cities with the introduction of high-pressure mercury vapour lamp (HME) luminaries. Later, they were changed to more energy-efficient high-pressure sodium vapour (HPS) lamp luminaries, which are still used as the primary technology around the world. Also, several quality standards (CEN/TR 13201 part 1-5) for measurements and maintained photometric parameter limits, adopted by many countries worldwide, were developed for this technology and continuously updated according to technological developments.

Introduction of high-power white Light-Emitting Diode (LED) by Shuji Nakamura led a new revolution in the lighting industry, making possible to install new luminary designs in street lighting applications. LED manufacturing companies (such as Cree, Philips, Osram) continuously improve the LED efficiency (Lm/W) ratio, at the same time also decreasing the LED costs, which also affects the final costs of the LED luminary at the end-user side. LED luminary total lumen (see Fig. 1) output is influenced by many factors during the luminary manufacturing process. Therefore, the initial LED chip manufacturer efficiency (Lm/W)
Peteris Apse-Apsitis, Leonids Ribickis

Smart City Street Lighting System Quality and Control Issues to Increase Energy Efficiency and Safety 


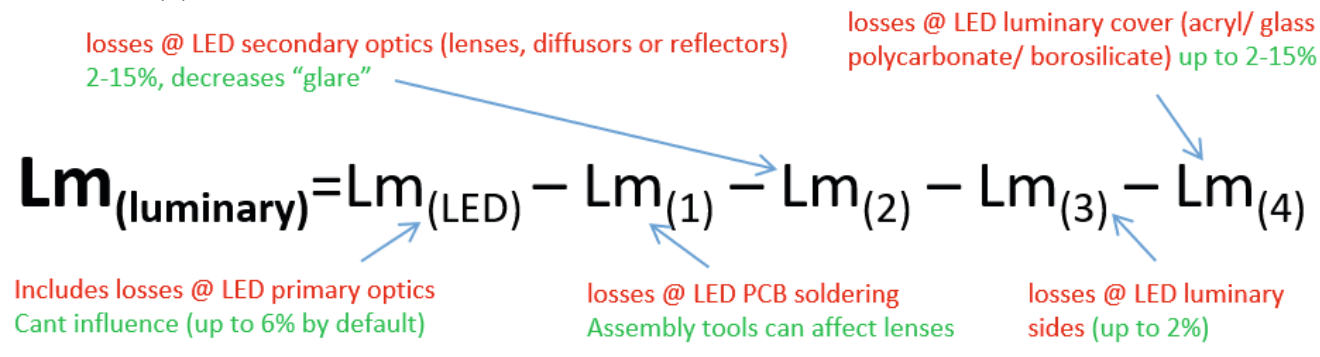

Figure 1. Typical places of total luminary lumen losses in LED luminary manufacturing process

decreases, creating a considerable difference between light source efficiency and luminary efficiency.

The LED luminary total power consumption (W) is determined by the nominal power of the light source (LED), summed with LED driver (power supply) losses and also the consumption of other peripherals, like sensors, communication and control nodes. Many parameters can lead to various interpretations in LED luminary datasheets and Dialux (Dialux EVO) type software modelling input data precision, affecting the overall street reconstruction project or luminary retrofit plan, as wrong power maximum or LED luminary itself can be selected. Furthermore, the choice of proper LED chip (see Fig. 2) for the application field (street, indoors, decorative, park, for example) can have large differences in overall efficiency. We can see that small-size LEDs are more efficient

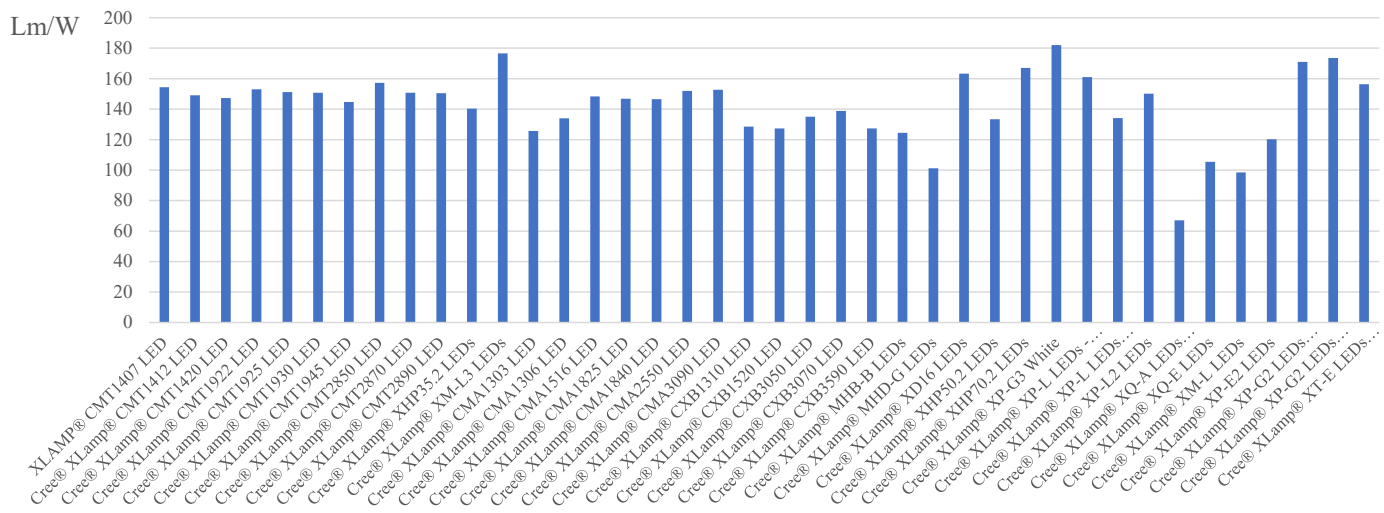

Figure 2. Cree LED manufacturer different LED chip comparison in terms of efficiency $(\mathrm{Lm} / \mathrm{W})$, date obtained at the end of 2020 


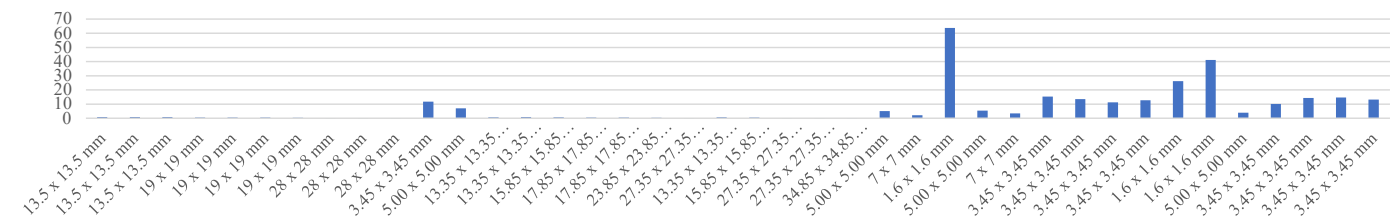

Figure 3. Cree LED manufacturer different LED chip comparison in terms of efficiency $\left(\mathrm{Lm} / \mathrm{W}\right.$ per its size in $\mathrm{mm}^{2}$ ), data obtained at the end of 2020

(see Fig. 3), but not applicable to street luminary design due to low power and light output.

As street profile geometrical properties and LED luminary quality parameters can vary, we can state that Dialux modelling results can have large errors in specific parts of street compared to in-situ measurements, using decreased safety (light quality is too low) or increased energy consumption (there is too much light). Further, the article will reveal some practical results of PilotSite measurements in Latvia for the period of 2009-2020, in the meantime also introducing to a lighting system advancement timeframe.

\section{General aspects of street lighting evaluation}

\subsection{Related standards}

For LED luminary, lighting pole, cables, communication and control equipment, many quality and safety-related standards have been developed that are mandatory in EU countries. Some are related to electrical quality (Low Voltage Directive and Electromagnetic Compatibility), others - to components used (RoHS and WEEE), housing (IP and IK class), light hazard to vision, etc. Latvian standard LVS CEN/TR 13201-1:2015 is directly related to safety and quality parameters on the street (or road) lighting, as it provides guidelines for the selection of lighting classes and is a part of EN13201 standard group (CEN/TR standards, parts 1-5). This standard was updated in 2015, introducing four-time intervals $\left(\Delta t_{1}\right.$ : ON time till evening rush hour, $\Delta t_{2}$ : evening rush hour till midnight, $\Delta t_{3}$ : midnight till morning rush hour, $\Delta t_{4}$ : morning rush hour till OFF time) for road lighting operation time. The need for such time intervals is that nowadays LED luminary power supplies can be programmed or controlled by PWM, 0-10VDC or DALI signals. Smart city lighting systems (Kuusik, et al., 2016) are equipped 


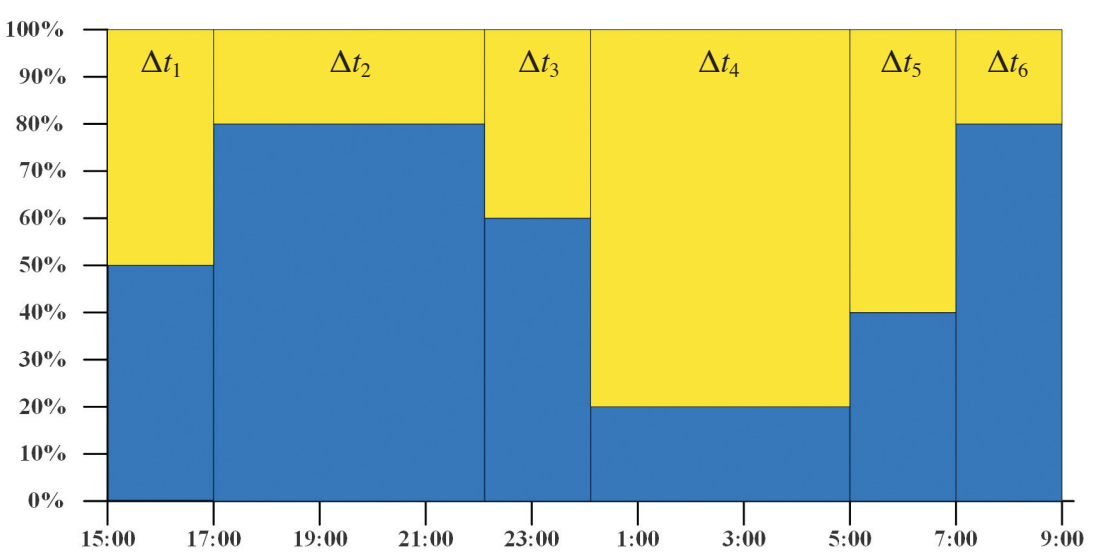

Figure 4. LED luminary nighttime intervals and programmed power output minimums/maximums for the movement sensor triggering signal control

with motion detection sensors or remote-control systems (Avotins, et al., 2014), thus promoting additional energy savings, utilising sensortriggered luminary switching ON/OFF in minimum or maximum power (light output). Moreover, it could be mentioned that some manufacturers create even more time intervals as shown in Fig. 4.

Each of these time intervals can have six different lighting classes for motorised traffic $(M)$ (in Dialux versions it can be named ME1 - ME6) or conflict areas $(C)$, also specified with quality parameters (average luminance $L, U_{0}, U_{1}, f_{\mathrm{T} 1}, R_{\mathrm{EI}}$ ) by "Part 2" of this standard. The number of $M$ class is determined by Eq. (1), using the sum of weighting (range: $-2 \ldots 0 \ldots+2)$ values of each criterion, such as design speed or speed limit, traffic intensity (\% of max capacity), traffic composition, separation of the carriageway, junction density, parked vehicles, ambient luminosity, navigational task.

$$
M=6-\Sigma V W_{i} M
$$

\subsection{Modelling in Dialux type software}

When ME class number is determined for a particular road, it is possible to calculate light output quality parameters in modelling software like Dialux 4.0, Dialux EVO, Relux and similar for a particular LED luminary on lighting poles. Initially, all street profile geometrical parameters $(a, b, c, d, \alpha)$ must be obtained (Fig. $5 b$ ), such as type of road tarmac, lighting pole placement, traffic and pedestrian lane count, traffic directions and grass zones. In Latvia, two situations are 


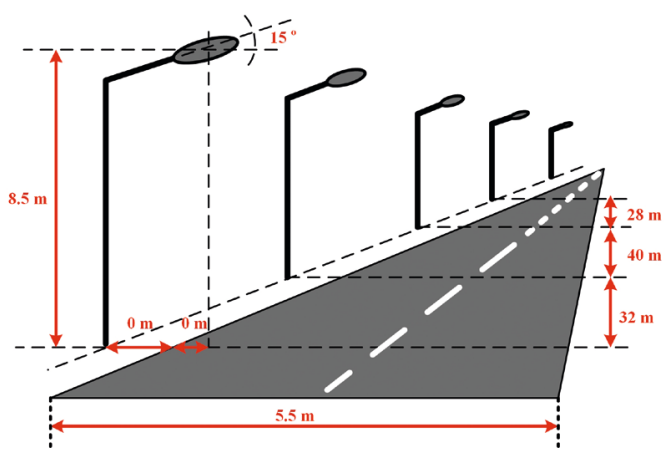

a)

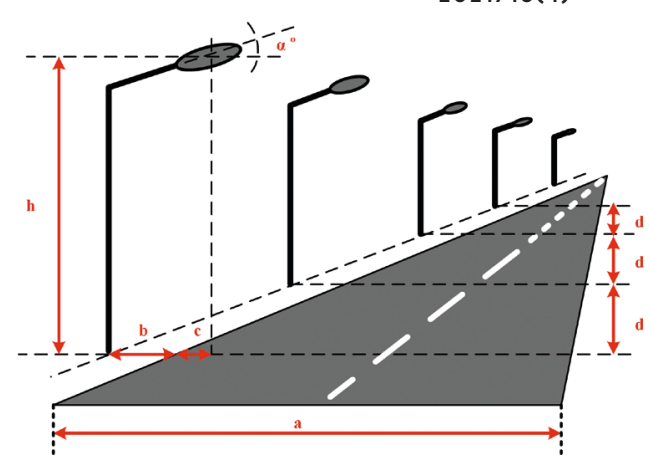

b)

Figure 5. The necessary geometrical input data for Dialux light distribution calculations

$$
d=\frac{\sum L_{n}}{n}
$$

possible, where pole distance is constant, typical of new or central streets of the city with steel poles (Fig. 5b), or with various pole distances (Fig. 5a), typical of old and smaller streets in rural parts of the city, mostly concrete or wooden based poles. It is difficult to carry out Dialux calculations for each pole distance; therefore, it is common in the industry to calculate average distance per street (Fig. 6), using Eq. (2) to have constant value $d$. This unified approach has an impact on safety and energy efficiency.

Standards also determine LED luminary light distribution measurements in $(C, \gamma)$ system, where $C$ is semi-plane every 5 degrees and $\gamma$ - gamma angles every 2.5 degrees. After these measurements are performed in the laboratory (using goniophotometer), a luminary light

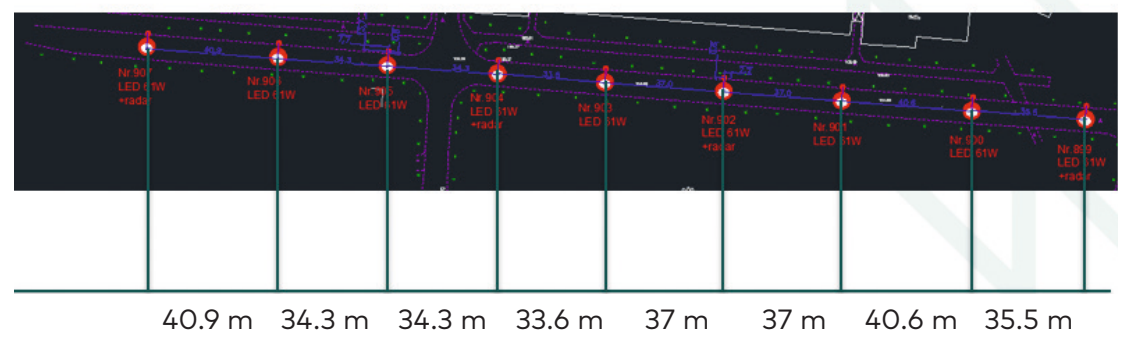

Figure 6. Sample of AutoCAD format (*.dwg file) topographical layout for street lighting with various pole distances 
Table 1. The main lighting parameters describing safety performance of a road lighting system

\begin{tabular}{|c|c|c|c|}
\hline Parameter & Formula & & Notes \\
\hline $\begin{array}{l}\text { Illuminance, } \\
E_{1} \text { lux }\end{array}$ & $E=\frac{\Phi}{A} \times \cos \alpha$ & (3) & $\begin{array}{l}\text { Can be measured } \\
\text { with luxmeter }\end{array}$ \\
\hline $\begin{array}{l}\text { Light intensity, } \\
\text { I, cd }\end{array}$ & $I=\frac{\Phi}{\omega}, I \approx \frac{E \times r^{2}}{\cos \alpha}$ & (4) & $\begin{array}{l}\text { Can be measured } \\
\text { with luminance candela meter }\end{array}$ \\
\hline $\begin{array}{l}\text { Luminance, } \\
L, \mathrm{~cd} \cdot \mathrm{m}^{-2}\end{array}$ & $L=\frac{I}{A}$ & (5) & $\begin{array}{l}\text { Can be measured } \\
\text { with luminance meter }\end{array}$ \\
\hline $\begin{array}{l}\text { Threshold } \\
\text { Increment, } \\
T I, \%\end{array}$ & $T I=\left(\frac{k \times E_{e}}{L_{a v}^{0.8} \times \Theta^{2}}\right) ; k=641 \times\left[1+\left(\frac{A}{66.4}\right)^{4}\right]$ & (6) & $\begin{array}{l}\text { Calculated from measurable } \\
\text { values, } k \text { is a constant } \\
\text { depending on age }(A) \text { of the } \\
\text { observer }\end{array}$ \\
\hline $\begin{array}{l}\text { Maintenance } \\
\text { Factor, MF }\end{array}$ & $\begin{array}{l}M F=(L L M F \times L S F) \times L M F \times R M F \\
L L M F \text { - lamp lumen maintenance factor } \\
L S F-\text { lamp survival factor } \\
L M F \text { - luminaire maintenance factor } \\
R M F \text { - room maintenance factor } \\
S M F \text { - surface maintenance factor }\end{array}$ & (7) & $\begin{array}{l}\text { Calculated from street, } \\
\text { manufacturer datasheets/ } \\
\text { test reports, maintenance } \\
\text { performed, etc. }\end{array}$ \\
\hline
\end{tabular}

distribution file in *.ies or *.ldt format can be obtained from luminary manufacturer and used for Dialux simulations. According to Czyżewski (2018), the more accurate the measurement step of $C$ and $\gamma$ angles, the more realistic modelling results can be obtained afterwards. This can influence the overall safety on the road, as too much light has an impact on Threshold Increment $\left(f_{\mathrm{TI}}\right)$, which is a measure of disability glare expressed as the percentage increase in contrast required between an object and its background for the object to be seen equally well with a source of glare present (luminary itself and road surfaces, especially if wet).

After Dialux calculations, the software gives resulting values of quality parameters (average luminance $L, U_{0}, U_{\mathrm{l}}, \mathrm{f}_{\mathrm{T}}, R_{\mathrm{EI}}$ ) and fulfils the minimum requirements of the EN 13201 standard. Also, it gives light distribution across the street surface in candelas $(I)$ or lux $(E)$ values, using the isoline curve 2D graph of the predefined resolution matrix. This way we can select the resolution matrix $(4 \times 11$ points or more) according to our street width and pole distance to measure those values after luminary installation and compare them with Dialux simulation results. If such a procedure is performed, then the street quality and safety can be increased, and potential energy will decrease, especially if too powerful LED luminary has been installed in the specific road 
part. Table 1 gives an overview of the main parameters used in Dialux modelling and formulas that can be used for measurement analysis or the obtained result comparison.

\subsection{Road lighting safety issues and different perspectives}

The lighting system has evolved to "smart lighting system", exploiting integrated ICT nodes and getting the ability to control and monitor individual LED luminaries. Nevertheless, the high system installation costs and low ROI values have added additional value to the lighting system, becoming an essential part of what we call "Smart City". Thus, now we have different perspectives of such a system, as we can distinguish city level, road user level and lighting system component level.

At the city level, the municipality (or subcontracted lighting maintenance company) is interested in keeping the maximum traffic safe at the lowest operating costs and potentially adding new functions \& services. In this way, it is a mix of needs. Depending on a decisionmaker and available budget, the focus and strategies can differ, but the budget issues will always prevail over the safety. The typical solution in Latvia for HPS luminary lit streets is to switch OFF 2/3 of phases, and it means that each third light pole is ON. In smart LED luminaries, they can be dimmed, thus keeping at least some safety level, even it will not fulfil the ME class criteria. The luminary damage or even complete street blackout due to cable damage can be detected by individual luminary communication fail, or by using computer vision and image data processing to remotely localize and monitor blackouts (Zanjani et al., 2013). In large and wealthy cities, a smart LED lighting system is a key to decreasing human work maintenance costs. However, in smaller cities it could be a problem to find damaged LED or HPS luminary (or trace the lumen deprecation); thus, traffic users or volunteers could help maintain urban safety by using smartphone application-based idea (Alam et al., 2020), which is scanning lighting parameters under to pole, while the user is riding a bike.

At the user level, it is expected that the roads and streets are safe and lighting is available as much as possible, since studies (Mattoni et al., 2017) show that pedestrian safety perception (and also evaluation) is linearly related to the mean horizontal illuminance. It also means no blackouts, stable light output, long lifetime, high-quality products, resulting in higher installation and operating costs. The main complaints to smart city lighting systems are unused white-spectrum of LED light compared to yellowish HPS light, if sensors attached to speed up (up to 1 second) light ramp-up un ramp-down times turning light ON and OFF create "disco effect" annoying the people. So far, the slow ramp-up time 
slope (1-3 seconds) helps the human eye adapt to light changes and eliminates this problem.

At some point it could be possible that the city and user levels start to interact, as described in the article about hybrid city lighting (Siess et al., 2015), where it is suggested that the street can become a display, thus enabling interactivity and increasing safety for pedestrians (especially children). The main focus is placed on attracting pedestrian attention to dangerous situations (for example, pavement, street crossing) using visualization and game elements such as "soccer", "footprints", "the floor is lava", "clear ice detection". The car traffic user can also be notified, for example, by sending a visual warning that can be seen ahead, especially useful if a child runs onto the street unexpectedly hiding behind car/bus (not visually detectable by the car driver).

Interaction between the user levels can also be obtained; to increase safety on streets, the exciting idea is to implement a "panic button" (Priyanka et al., 2019), which can be installed in light poles and help road users in case of an emergency (car accident, unexpected health problems, or any other "112" case). An integrated microphone or web-cam can improve the safety and data reliability even further, as the system can send some additional information to the central system for proper decision making.

At the system component level, the challenge is the highest. Here, demands from the city level and the user level must be fulfilled; thus, the system, component design and production require a lot of knowledge and continuous improvements. For example, we know that power LED chip used for street lighting emits blue light, and a phosphoric layer makes this light in the white spectrum of visible light. The dominant wavelengths depend on the materials used by LED manufacturer, and a luminary manufacturer typically uses 1 type of LEDs on the same PCB as the light source. One of the spectrum parameter related studies (Maierová, 2018) deals with safety and visual comfort on the streets, as the sensitivity of the human eye, according to CIE Purkinje shift and activity of photoreceptors, differs during nighttime (scotopic, mesopic and photopic visual function). Red+Amber LED biodynamic lighting is introduced to stimulate user perception during evening and morning rush hours biologically, and non-stimulating lighting for rest in the nighttime (blue LED spectrum is switched OFF) also helps decrease biological impact on wildlife and not disturb resident sleep.

The manufacturer is willing to sell the product; therefore, the product must have a low price, long lifetime and good ROI values. For this reason, it is a tradeoff of price, component selection, compatibility, quality and functionality. The electrical safety of lighting system starts with protection against indirect contact (automatic power supply 
disconnector) and good TT, TN-C or TN-S grounding system selected (Parise et al., 2011), further, the luminary and AC-grid connecting wires should have Class II reinforced insulation to be installed in metal poles. Another safety aspect is a lightning strike that can hit one luminary and pass to the next luminaries through lighting grid, thus destroying a large number of luminaries or even the whole street. In this case, a protecting device can be used to avoiding such damage, but once again it affects the end-price of product.

The street profile and street crossings can also experience dangerous situations, such as multilane crossing, low visibility conditions, oblique crossing of lanes, absence of adaptive zones, crossing outside a marked pedestrian crossing. The study (Bláha et al., 2014) shows that cloth luminance decreases nine times in such cases (from $17.7 \mathrm{~cd} / \mathrm{m}^{2}$ to $0.5 \mathrm{~cd} / \mathrm{m}^{2}$ ). Thus, proper CE class selection is essential. Post-installation measurements should be mandatory, especially if Charge-Coupled Devices (CCD) or cameras (Armas et al., 2007), like LMK Mobile Air, are available on the market. Such preliminary or approximate validation (Kuusik et al., 2016) can save much time and allow for the analysis of many parameters.

\section{Light control for smart street lighting}

\subsection{Smart street lighting system components}

Smart street lighting systems have several main system components, as shown in the LITES project example (see Figs. 7 and 8a). Management software communicates with ZigBee gateway through the Ethernet network, mainly taking readings of luminary status, power consumption, and updating light control profiles to the luminary or the gateway. The gateway communicates by ZigBee mesh network with the LED luminary "control node", which is an electronic device/controller that reads the signal from a motion detection sensor (True/False status

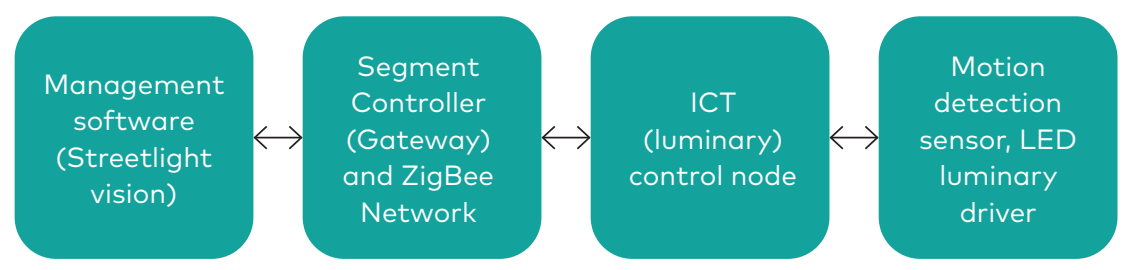

Figure 7. Smart street lighting system layout created in LITES project and used in Riga PilotSite
Ansis Avotins, Leslie Robert Adrian, Ricards Porins, Peteris Apse-Apsitis, Leonids Ribickis

Smart City Street Lighting System Quality and Control Issues to Increase Energy Efficiency and Safety 
a)

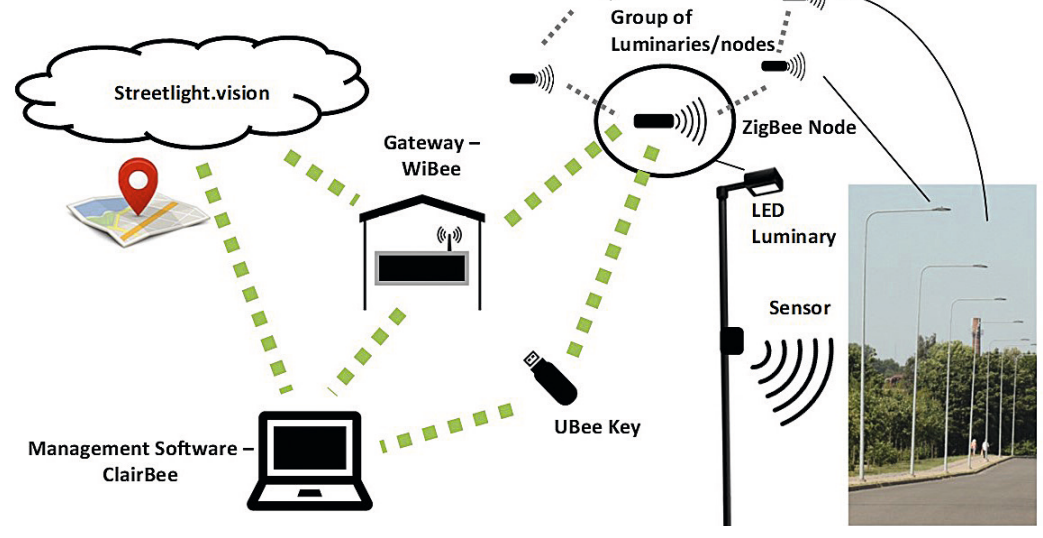

\begin{tabular}{|c|c|c|c|c|c|c|c|c|c|c|}
\hline \multicolumn{11}{|l|}{ ר Clairßee } \\
\hline \multirow{2}{*}{\multicolumn{11}{|c|}{ 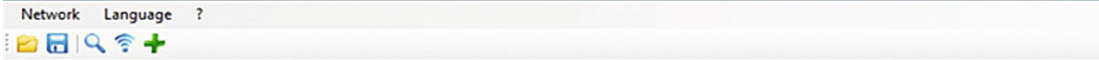 }} \\
\hline & & & & & & & & & & \\
\hline \begin{tabular}{|l|l|l|}
8 & $(1) 1)$
\end{tabular} & $\begin{array}{l}\text { UTTES95_01 } \\
\text { (C2:90) }\end{array}$ & $\begin{array}{l}\text { UTES955_02 } \\
\text { (BEC2) }\end{array}$ & $\begin{array}{l}\text { UTES95_03 } \\
(B E F F)\end{array}$ & $\begin{array}{l}\text { LITES95.04 } \\
(C 2 A B)^{-04}\end{array}$ & $\begin{array}{l}\text { UTIES95_05 } \\
\text { (C1:CF) }\end{array}$ & $\begin{array}{l}\text { UTIES95_06 } \\
\text { (C1:E7) }\end{array}$ & $\begin{array}{l}\text { UTTES95_07 } \\
\text { (C1:C5) }\end{array}$ & $\begin{array}{l}\text { LTTES95.08 } \\
\text { (C2C(3) }\end{array}$ & $\begin{array}{l}\text { UTIES95_09 } \\
(C 205)^{-09}\end{array}$ & $\begin{array}{l}\text { UTESS95_10 } \\
(C 200)\end{array}$ \\
\hline $\begin{array}{l}\text { UTES95_01 } \\
\text { (C290) }\end{array}$ & $\nabla$ & $\nabla$ & $\square$ & $\square$ & $\square$ & $\square$ & $\nabla$ & $\nabla$ & $\nabla$ & $\nabla$ \\
\hline $\begin{array}{l}\text { LTTES95_02 } \\
(\mathrm{BEC} \text { (2) }\end{array}$ & $\nabla$ & V & 四 & 四 & 뭉 & 口 & 四 & $\nabla$ & $\nabla$ & v \\
\hline $\begin{array}{l}\text { LTTES95_03 } \\
\text { (BEFB) }\end{array}$ & ( & $\nabla$ & $\nabla$ & $\square$ & 曰 & 口 & $\square$ & 口 & च & च \\
\hline $\begin{array}{l}\text { UTESS95_04 } \\
(C 2 A B)^{-}\end{array}$ & 四 & 呵 & ( & 呵 & 口 & 口 & 口 & 口 & 口 & 『 \\
\hline $\begin{array}{l}\text { UTES95_05 } \\
\text { (CI:CF) }\end{array}$ & 『 & $\nabla$ & $\nabla$ & 呵 & v & $\square$ & $\square$ & $\square$ & 口 & E \\
\hline $\begin{array}{l}\text { LITES95_06 } \\
\text { (CI:ET) }\end{array}$ & 口 & v & 甲 & $\nabla$ & $\nabla$ & $\nabla$ & 四 & 目 & 回 & 口 \\
\hline $\begin{array}{l}\text { LTES95_07 } \\
\text { (CIC5) }\end{array}$ & $\square$ & $\square$ & 甲 & 回 & ㅁ & 甲 & 四 & 口 & $\square$ & 口 \\
\hline $\begin{array}{l}\text { UTESS5_OB } \\
\text { (C2:C3) }\end{array}$ & 四 & $\square$ & $\square$ & 四 & v & 四 & 四 & 四 & 四 & 口 \\
\hline $\begin{array}{l}\text { LTTES95_09 } \\
(C 2.05)\end{array}$ & 四 & 口 & 四 & $\square$ & v & $\nabla$ & V & $\nabla$ & 四 & 四 \\
\hline $\begin{array}{l}\text { LITES95_10 } \\
\text { (C2.00) }\end{array}$ & 口 & 四 & 四 & 四 & $\square$ & $\nabla$ & $\nabla$ & $\nabla$ & $\nabla$ & $\nabla$ \\
\hline
\end{tabular}

b)

Figure 8. LITES smart LED lighting system (a), luminary network configuration (b)

signal) and sends a control signal (PWM, 0-10VDC, DALI) to the LED driver (power supply). Luminary configuration is performed by the gateway, by sending configuration files directly to a specific luminary, using UBee key (ZigBee communication stick) and software on laptop computers to communicate directly (in-situ) with LED luminary network. Sensor and luminary network association/configuration form is shown in Fig. 8b. It is easy to control five LED luminaries when one motion sensor is triggered, furthermore - as the distance between poles is $33 \mathrm{~m}$ typically, it can lit light (to max value) 3 or 5 luminaries ahead, reaching the distance of 100-160 m, which is very safe for visual identification of obstacles or in case a car must stop rapidly. 
Movement detection sensor reads the movement and utilising a "dry contact" closes the relay output, and the control node understands that movement is happening; another luminary control node sends a "MAX level" signal/value of the predefined time interval (Fig. 4) to the LED luminary driver (Fig. 9a). When the sensor does not detect any movement, the contact releases (is open) and LED luminary gets a "MIN level" signal.

\subsection{Dimming or light output control}

In many control systems, the light output level or "dimming" control is implemented by linear means, assuming that LED luminary power output is proportional to the luminary light output value. From LED diode (Fig. 9b) measurements, we can see that this is not entirely true,

a)

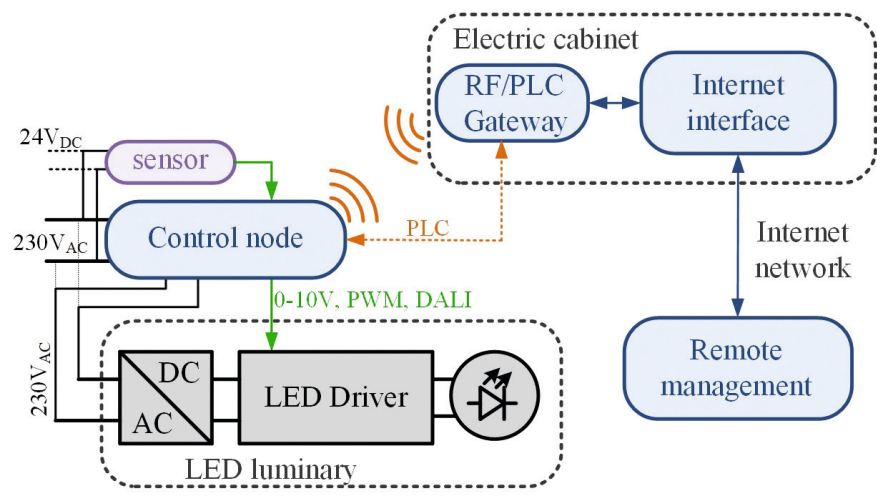

b)

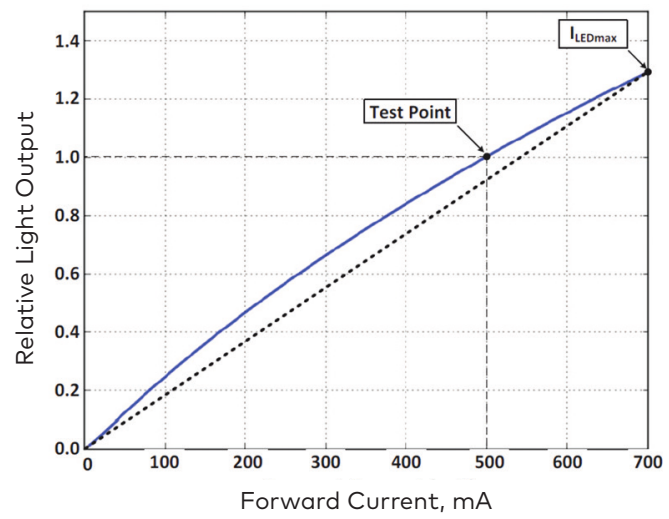

Figure 9. A sample of smart lighting LED luminary (a), and the relation between LED current and light output (b)

\section{Leonids Ribickis}

Smart City Street Lighting System Quality and Control Issues to Increase Energy Efficiency and Safety 
as LED diode volt-ampere characteristic is also nonlinear. By higher forward currents (A), the p-n junctions heat up more, also causing less light to be emitted, unless adequately cooled. Typically, LED luminaires have passive radiators; therefore, they cannot be entirely cooled down to avoid this impact at high currents.

Thus, depending on a LED luminary PCB design, nominal forward current (power) and LED driver feedback signal type, we can get around $8 \%$ error in light output, regulating the luminary in the $20-100 \%$ interval.

The same linearized light output and power relation approach is used for Dialux calculations to model the light parameters in the dimmed regime of the luminary, to check compatibility with ME class in dimmed regime, which typically is lower if the needed light amount is reduced. Therefore, we can assume that additional precision errors can also be found at this stage, causing too much light at specific power values. It can affect glare values in marginal cases. However, if Dialux calculations show ME or CE class compatibility, then the chance is really low, and safety should not be affected. However, in terms of energy efficiency, we could find extra savings here.

\subsection{The existing control methods for dimming}

The existing control methods of switching ON/OFF luminaries or even whole streets/districts are calendar-based. Each day of the year has different sunrise and sunset times, and city lighting is adapted. This method has been known for a very long time and is the most commonly used method for HPS luminary lighting. An upgrade to this system adds a photo-sensor to the transform substation or electric cabinet, controlling whole streets. HPS luminaires can be dimmed till a certain level $(60-70 \%)$ of nominal power, using voltage regulation techniques, but LED luminaries - in the range of $1-100 \%$. As some ballasts are programmable (built-in astronomic calendar, for example), they can have different power levels through certain time intervals of the night. These focus on energy consumption reduction, but only partly considering the safety or lighting quality issues on the road, as traffic intensity data are "assumed" values in specific periods. Next step in lighting control is to exploit the opportunities of movement detection sensor data. It can obtain periodic traffic count (intensity) data or even the direction and speed of traffic (Adrian \& Ribickis, 2014). A car is a typical traffic user. Compared to a pedestrian, detecting a car can reduce danger for all traffic users; therefore, detection precision does not need to be of very high accuracy. Virtual sensors as context application (Avotins \& Bicans, 2015) data from other systems can also be used to reduce energy 
consumption by $76 \%$ compared to the non-controlled LED lighting system.

In terms of hardware and software for smart lighting systems, many studies have been performed recently, and logical next questions lie in safe and energy-efficient control algorithm development. Even for LEDs, a Brute force algorithm (Mahoor et al., 2017) can be applied, as it uses movement sensor statistical data of previous periods to evaluate lighting levels (controls HPS luminary power). The approach is simplified and focuses on energy efficiency. The disadvantage is the safety issue, as the only element considered is the rush-hour time interval, where the algorithm is limited in dimming capabilities. Also, the HPS luminary power (150 $\mathrm{W}$ typically is bulb power) and light output relation are assumed to be linear, raising doubts about light quality on the street and compliance to the ME classes. Theoretical energy savings for Lighton-Demand model, considering traffic uniformity, speed and distance to stop it safely, is described in the research (Cela et al., 2019). It also includes symmetrical dimming around the car (from min to max level). It seems to be better suited for long and straight streets. It looks very complicated, as it uses SUMO model and does not calculate the required luminary power level according to current traffic amount.

A very promising LED lighting control strategy proposed in the research (Shlayan et al., 2018) considers traffic and road characteristics combined with traffic sensor data to determine ME class and exploiting Greenshields' Traffic Model. As a result, in two use cases, 86\% and 89\% power $(\mathrm{P}, \mathrm{W})$ reduction per pole can be achieved if compared to a non-controlled LED luminary case. To predict a traffic user behavior, Cellular Automata (CA) models (Yang et al., 2015), both for vehicle traffic and pedestrian, exploiting zone movement detection sensor data and interpreting the direction and path, make use of lighting control strategies of Light-on-Demand to next four LED luminaries.

\section{PilotSite and experimental analysis}

\subsection{LED luminary tests for the period of 2009-2012}

Initially, LEDs were designed for retrofit purposes (to replace HPS bulbs or whole luminary). In 2009, we were able to test first products in Riga (Latvia) PilotSite within Zunda Krastmala street premises (see Fig. 10a). At that time, LED was a new technology, and a lack of detailed technical data was a common problem for an end-user (like a municipality) to evaluate the quality. As in most cases, manufacturers (also wholesalers) declared incorrect or approximate time values, at the
Ansis Avotins, Leslie Robert Adrian, Ricards Porins, Peteris Apse-Apsitis, Leonids Ribickis

Smart City Street Lighting System Quality and Control Issues to Increase Energy Efficiency and Safety 
a)

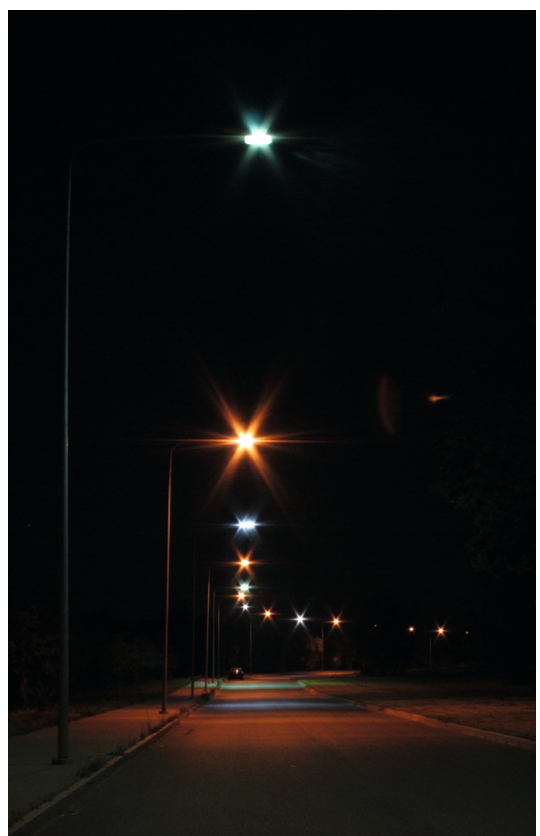

b)
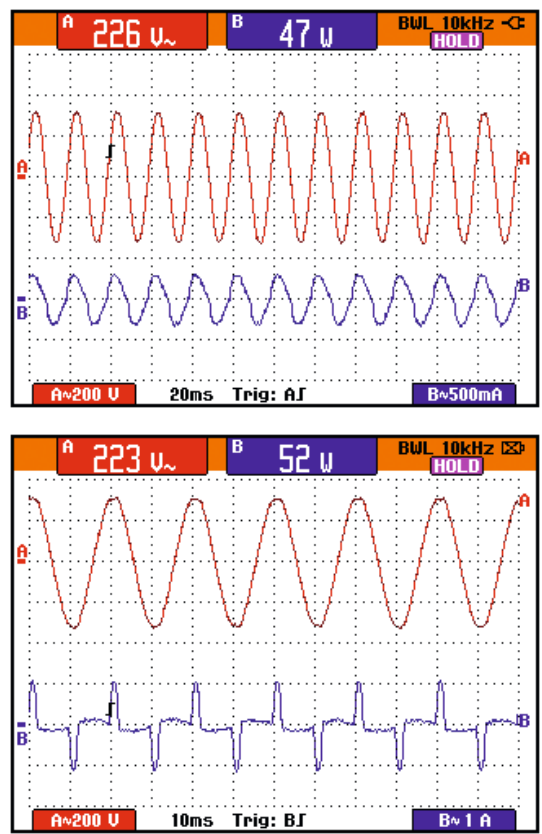

c)

Figure 10. Results of measurements performed in 2009: a - picture of dry road PilotSite in Riga; $b-A C$ voltage and current waveform for Cobrahead 48.7W luminary; c - AC voltage and current waveform for Diodella $52 \mathrm{~W}$ luminary

same time keeping high prices (Joliet J0L6 225W sales price was around 1200 EUR and others were around 800-900 EUR, the retrofit bulb was around 200 EUR), which decreased the trust in LED technology itself.

In Table 2, we can observe initial parameters compared to laboratory and PilotSite measurement results. We can also observe that luminary efficiency was different by light colour temperature. The warm-white region $(4000 \mathrm{~K})$ was $48.5 \mathrm{Lm} / \mathrm{W}$, and in the region of blue light $(6000 \mathrm{~K})$ it reached $60 \mathrm{Lm} / \mathrm{W}$. Low power (or light output) allowed using these LED luminaires only on streets with ME5 or lower classes, and ME2 class was reached only by high power and blue light spectrum luminary. Also, the large difference of LED colour temperature compared to the yellow/orange colour of HPS was not well accepted by traffic users, if analysing more in details - it was also due to glare when entering the LED luminary zone. The consumed reactive power $Q$ (VAR) is another quality-related issue. In Fig. 10, we see two different current waveforms: 
Table 2. The main parameters of SMD/SMT based LED luminary tested in LAB and Riga PilotSite in 2009

\begin{tabular}{|c|c|c|c|c|c|}
\hline Luminary & $\begin{array}{c}\text { Lumens, Lm } \\
\text { (by manufacturer) }\end{array}$ & $\begin{array}{c}\text { Power } \\
\text { measured, W }\end{array}$ & $\begin{array}{c}\text { Temperature } \\
\text { colour, K }\end{array}$ & $\begin{array}{c}\text { Efficiency, } \\
\text { Lm/W }\end{array}$ & $\begin{array}{c}\text { ME class } \\
\text { qualified }\end{array}$ \\
\hline $\begin{array}{c}\text { GE Cobrahead } \\
25 W\end{array}$ & $1203(48.12 \mathrm{Lm} / \mathrm{W})$ & 24.8 & 4500 & 48.5 & ME5 \\
\hline $\begin{array}{c}\text { GE M250 } \\
\text { Cobrahead 48.7W }\end{array}$ & $2235(45.89 \mathrm{Lm} / \mathrm{W})$ & 47 & 4500 & 47.55 & ME5 \\
\hline $\begin{array}{c}\text { Joliet 28W } \\
\text { retrofit bulb) }\end{array}$ & $2100(75 \mathrm{Lm} / \mathrm{W})$ & 35 & $5500-6500$ & 60 & ME5 \\
\hline $\begin{array}{c}\text { Joliet JOL6 225W } \\
\text { (street lamp) }\end{array}$ & $12600(56 \mathrm{Lm} / \mathrm{W})$ & 219 & $5500-6500$ & 57.53 & ME2-ME5 \\
\hline $\begin{array}{c}\text { Diodella } \\
(84 \text { LEDs) }\end{array}$ & N/A $(80 \mathrm{Lm} / \mathrm{W})$ & 52 & 4100 & $\mathrm{~N} / \mathrm{A}$ & ME4-ME5 \\
\hline Starium Dragon & $2367(57.73 \mathrm{Lm} / \mathrm{W})$ & Not measured & 5600 & N/A & Not measured \\
\hline Cobrahead (80W) & $4749(59 \mathrm{Lm} / \mathrm{W})$ & Not measured & $5500-6500$ & N/A & Not measured \\
\hline
\end{tabular}

Note: In 2009, LED datasheets did not include detailed technical data.

luminary GE M250 Cobrahead 48.7W ( $Q=17$ VAR, $\cos \varphi=0.97$ ) (Fig. 10b) and luminary Diodella $52 \mathrm{~W}(Q=70.73 \mathrm{VAR}, \cos \varphi=0.95)$ (Fig. 10c).

The end of the year 2010 marked another test that was performed at RTU laboratory and on another street of Riga, testing three different power Photon-L street luminaries named "PH-ST", see the results in Table 3. Total LED luminary efficiency value (Lm/W) was not correctly identified in many datasheets. Lumen value was used from the LED light source (diode), ballast/driver consumption was not included in total power, creating confusion in procurement tenders for end-users. The waveform of Photon-L luminary voltage and current consumption was measured as sinusoidal (PF 0.97) because an LED driver with an integrated PFC circuit was used.

Dialux v4.10, Relux and similar light output simulation software tools, to check the luminary quality (street) on a specific street, were not very

Table 3. The main parameters of photon-L LED luminary tested in LAB and Riga PilotSite in 2010

\begin{tabular}{|c|c|c|c|c|c|}
\hline Luminary & $\begin{array}{c}\text { Lumens, Lm } \\
\text { (by manufacturer) }\end{array}$ & $\begin{array}{c}\text { Power } \\
\text { measured, } \mathbf{W}\end{array}$ & $\begin{array}{c}\text { Temperature } \\
\text { colour, } \mathbf{K}\end{array}$ & $\begin{array}{c}\text { Efficiency, } \\
\text { Lm/W }\end{array}$ & $\begin{array}{c}\text { ME class } \\
\text { qualified }\end{array}$ \\
\hline PH-ST-140 $(140 W)$ & $7081(50.57 \mathrm{Lm} / \mathrm{W})$ & 150.02 & $6000-7000$ & 47.20 & ME3-ME4 \\
\hline PH-ST-112 $(112 \mathrm{~W})$ & $5954(53.16 \mathrm{Lm} / \mathrm{W})$ & 124.55 & $6000-7000$ & 47.80 & ME4-ME5 \\
\hline $\mathrm{PH}-\mathrm{ST}-84(84 \mathrm{~W})$ & $5079(60.46 \mathrm{Lm} / \mathrm{W})$ & 107.42 & $6000-7000$ & 47.28 & ME5 \\
\hline
\end{tabular}


popular in Latvia. Typically, street reconstruction project architects and authors used an approximated approach, recommendation documents of manufacturers, basing only on luminary power and lumen output ratio, as the retrofit option was a choice between HME or HPS luminaires. In 2012, Latvia had a unique $\mathrm{CO}_{2}$ emission quota-based funding instrument (KPFI) enabled for municipalities to retrofit (partly reconstruct) old lighting system luminaries to a more energy-efficient LED technology. For this issue, such simulation tools became very widely used, as it was one of the application evaluation requirements.

For all Mamba luminaries, the same Cree diodes (CREE-XPG-R3) were used. A fascinating fact is that programmable power supplies were introduced in this application, which also caused installation or factory programming errors, as $97 \mathrm{~W}$ luminary was limited to $\sim 69 \mathrm{~W}$, as shown in all power measurements of Table 4, obtained during in-situ measurements. In 2012, dimmable power supplies (0-10 VDC) were more commonly used with the first control nodes - calendar-graph dimmers or five nighttime zones with minimum and maximum light output levels (for L56/L70 luminaries - Philips DynaDimmer). For both manufacturers' use cases, Dialux calculations were used (see Fig. 11a), in-cooperating the measured power consumption values to meet the real light output situation on the street. The obtained results (Table 5) in lux were compared with the measured lux values in the same spots on

Table 4. The main parameters of two LED luminaries tested in Incukalns city in-situ in 2012

\begin{tabular}{|c|c|c|c|c|c|}
\hline Luminary & $\begin{array}{c}\text { Lumens, Lm } \\
\text { (by manufacturer) }\end{array}$ & $\begin{array}{c}\text { Power } \\
\text { measured } \\
\text { in-situ, W }\end{array}$ & $\begin{array}{c}\text { Temperature } \\
\text { colour, K }\end{array}$ & $\begin{array}{c}\text { Lumens by Dialux } \\
\text { (Lm), Efficiency, } \\
\text { Lm/W }\end{array}$ & $\begin{array}{c}\text { ME class } \\
\text { qualified }\end{array}$ \\
\hline PLAZA L56 (56W) & $6300(>100 \mathrm{Lm} / \mathrm{W})$ & 51.1 & 5000 & $5610(@ 57.1), 98.25$ & ME6 \\
\hline PLAZA L56 (56W) & $6300(>100 \mathrm{Lm} / \mathrm{W})$ & 52.5 & 5000 & $5610(@ 57.1), 98.25$ & ME6 \\
\hline PLAZA L70 (70W) $)$ & $9100(>100 \mathrm{Lm} / \mathrm{W})$ & 46.7 & 5000 & $7200(@ 70), 102.85$ & ME5, ME6 \\
\hline PLAZA L70 (70W) & $9100(>100 \mathrm{Lm} / \mathrm{W})$ & 63.8 & 5000 & $7038(@ 70), 100.54$ & ME5, ME6 \\
\hline $\begin{array}{c}\text { Mamba A042B } \\
(97 W)\end{array}$ & $8447(>100 \mathrm{Lm} / \mathrm{W})$ & 69.8 & 5000 & $6959(@ 93 W), 74.83$ & ME5 \\
\hline $\begin{array}{c}\text { Mamba A042B } \\
(97 W)\end{array}$ & $8447(>100 \mathrm{Lm} / \mathrm{W})$ & 68.6 & 5000 & $6959(@ 93 W), 74.83$ & ME5 \\
\hline $\begin{array}{c}\text { Mamba A028B } \\
(60 W)\end{array}$ & $5512(>100 \mathrm{Lm} / \mathrm{W})$ & 67.5 & 5000 & $4971,73.65$ & ME5, ME6 \\
\hline $\begin{array}{c}\text { Mamba A028B } \\
(60 W)\end{array}$ & $5512(>100 \mathrm{Lm} / \mathrm{W})$ & 66.0 & 5000 & $4971,75.32$ & ME5, ME6 \\
\hline
\end{tabular}

Note: In-situ measurements can contain 5\% error in the current probe (power) measurements and control node consumption, explaining deviation in table power values. 
Table 5. Dialux modelling results of PLAZA L70 LED luminary in the real situation power/light output ratio (dimmed) regime

\begin{tabular}{|c|c|c|c|c|c|}
\hline $\begin{array}{c}\text { Dimmed regime } \\
\text { (as in a real situation) }\end{array}$ & $L_{\mathrm{av}, \mathrm{cd} / \mathrm{m}^{2}}$ & $U_{0}, \mathrm{~V}$ & $U_{1}, \mathrm{~V}$ & $T I, \%$ & $S R$ \\
\hline Obtained values & 0.44 & 0.39 & 0.48 & 11 & 0.76 \\
\hline $\begin{array}{c}\text { ME5 class minimum } \\
\text { requirements }\end{array}$ & $\geq 0.50$ & $\geq 0.35$ & $\geq 0.40$ & $\leq 15$ & $\geq 0.50$ \\
\hline $\begin{array}{c}\text { Class requirements } \\
\text { fulfilled or not }\end{array}$ & $\times$ & $\checkmark$ & $\checkmark$ & $\checkmark$ & $\checkmark$ \\
\hline
\end{tabular}

the street (see Fig. 11b). For LED luminary PLAZA L70 at full power of $70 \mathrm{~W}$, Dialux modelling, for $L_{\mathrm{av}}$, results from a result of $0.65 \mathrm{~cd} \cdot \mathrm{m}^{-2}$, thus fulfilling the ME5 class criteria.

Analysing the obtained results of Dialux (v.4) modelling (modelled $4 \times 11$ points), using Light Loss Factor "1.0" value in Maintenance Plan, and for new luminaries, it should have the same output on the street and real measured value (measured $4 \times 11$ points), we can see high difference throughout the whole street (see the difference in Fig.11b), in most cases more than $50 \%$, reaching even $150 \%$. In that period of time, such a street layout (length $41 \mathrm{~m}$ and height $8.3 \mathrm{~m}$ ) was very challenging for LED luminary optics, but such a high difference still could raise some doubts and questions.

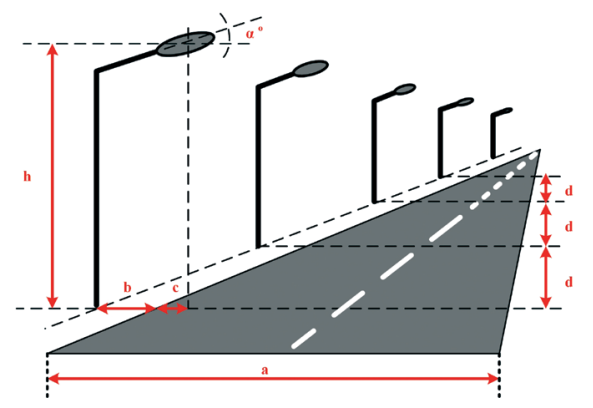

\begin{tabular}{|l|l|l|l|l|l|}
\hline$a$ & $b$ & $c$ & $d$ & $h$ & $\alpha$ \\
\hline $6 \mathrm{~m}$ & $4.4 \mathrm{~m}$ & $-0.9 \mathrm{~m}$ & $41 \mathrm{~m}$ & $8.3 \mathrm{~m}$ & $0^{\circ}$ \\
\hline Street layout & \multicolumn{4}{|l|}{ Surface/Tarmac } \\
\hline
\end{tabular}

a)

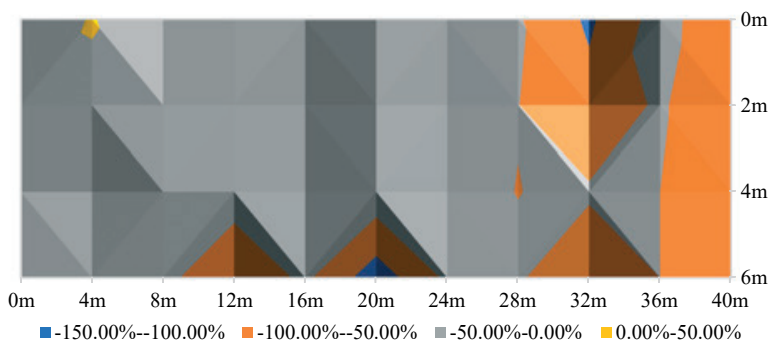

b)

Figure 11. Incukalns city street comparison in 2012: a - street profile; $b$ - comparative difference (\%) between the measured and modelled street profile values 


\subsection{LITES project results - PilotSite in Riga}

During the project implementation, a PilotSite was created on Kipsala island (Zunda Krastmala street) in Riga, where 29 pcs of existing HPS luminaires with a total power of $3450 \mathrm{~W}(18 \times 100 \mathrm{~W}$ and $11 \times 150 \mathrm{~W}$ HPS bulb) were replaced with LITES system (Fig. 8) using 29 pcs of Thorn Dyana LED luminaries (71.22 Lm/W, $4000 \mathrm{~K})$ with total installed power of $2215 \mathrm{~W}$ (18 pcs of $65 \mathrm{~W}$ and 11 pcs of $95 \mathrm{~W}$ ), to have equal or better quality and safety parameters. Decrease in the installed power was $54 \%$, but actually, it was more, as HPS electromagnetic ballast consumption was not included. PilotSite was simulated in Dialux v4 both for HPS and LED luminary arrangement (Fig. 12a), obtaining modelling results, later to be compared with in-situ measurements by a lux meter (Table 6), luminance meter and video-photoluminance meter in full power (maximum was $80 \%$ ) and dimmed state up to $20 \%$. Table 6 shows illumination (lux) values of Dialux simulation and in-situ measurements in the middle of the street, where M1 and M3 are under the pole and M2 is between the poles (see Fig. 13). We can see that in most cases the simulation shows less light (@MF 1.00) to be given by this LED luminary, if compared to measurements of the year 2014 and 2020, also in the dimmed stage.

The obtained energy savings of LITES smart lighting system using sensors were $72-73 \%$ in average per year. We can observe that during 7-year work (4400 hours per year) the lumen depreciation (light loss) is up to $20 \%$. However, the real values are still above the simulation results. We can conclude that the MF value is around 0.80 , and the LED luminary gives more light actualy than the manufacturer defines it.

Table 6. Dialux modelling results of LITES LED luminary in real situation power/light output ratio (dimmed) regime

\begin{tabular}{|l|c|c|c|c|c|c|c|c|c|c|c|c|}
\hline \multirow{2}{*}{$\begin{array}{l}\text { Illumination } \\
\text { points }\end{array}$} & \multicolumn{3}{|c|}{$E$ (80\%), Lux } & \multicolumn{3}{c|}{$E(\mathbf{6 0} \%)$, Lux } & \multicolumn{3}{c|}{$E(\mathbf{4 0 \% ) , ~ L u x ~}$} & \multicolumn{3}{c|}{$E(\mathbf{2 0 \% ) , ~ L u x ~}$} \\
\cline { 2 - 13 } & M1 & M2 & M3 & M1 & M2 & M3 & M1 & M2 & M3 & M1 & M2 & M3 \\
\hline $\begin{array}{l}\text { AVG } \\
\text { (Measured } \\
\text { in 2020) }\end{array}$ & 25 & 7 & 24 & 20 & 6 & 20 & 14 & 4 & 14 & 8 & 3 & 8 \\
\hline $\begin{array}{l}\text { Measured in } \\
\text { 2014 }\end{array}$ & 28 & 10.7 & 17 & - & - & - & - & - & - & 7.1 & 3 & 7 \\
\hline $\begin{array}{l}\text { Simulated in } \\
\text { 2014 }\end{array}$ & 20 & 8.19 & 20 & 10 & 4.49 & 10 & 6.24 & 2.92 & 6.24 & 3.12 & 1.35 & 3.12 \\
\hline $\begin{array}{l}\text { Difference } \\
\%\end{array}$ & $+19 \%$ & $-17 \%$ & $+17 \%$ & $+50 \%$ & $+21 \%$ & $+49 \%$ & $+56 \%$ & $+33 \%$ & $+56 \%$ & $+61 \%$ & $+49 \%$ & $+59 \%$ \\
\hline
\end{tabular}


Ansis Avotins, Leslie Robert Adrian, Ricards Porins,

Peteris Apse-Apsitis,

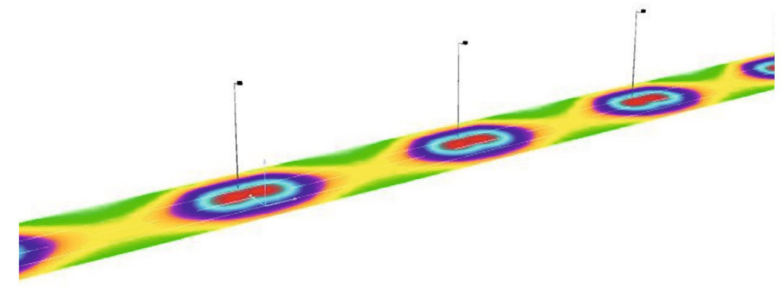

Leonids Ribickis

Smart City Street Lighting System Quality and Control Issues to Increase Energy Efficiency and Safety

a) Dialux simulation model (results of 150W HPS)

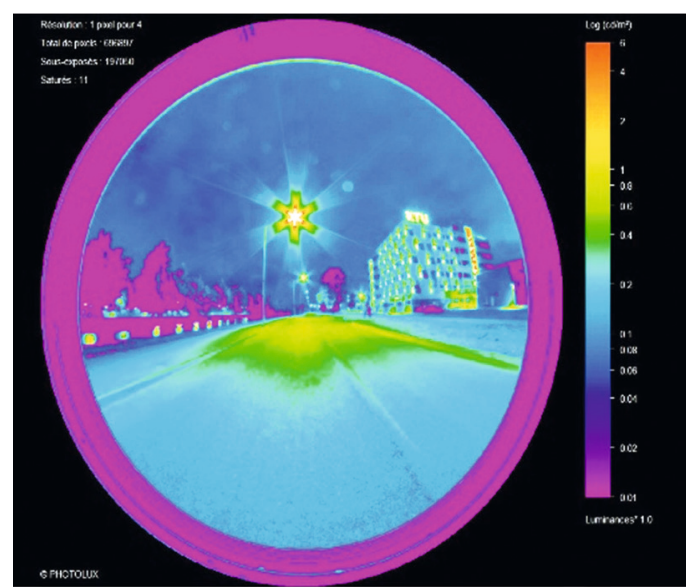

b) LED full power

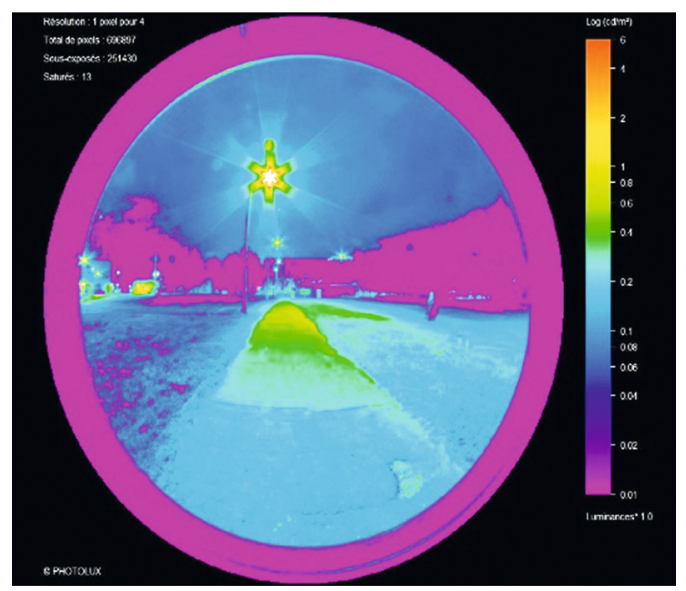

c) LED $20 \%$ power

Figure 12. LITES PilotSite: Dialux simulation results (a), Measurements of LED 95W luminary (b) and (c)

\subsection{Large smart lighting system measurements in 2020}

Small pilot sites do not give precise analytic results to make a general conclusion. If Dialux simulations give lower light output results than in reality they can be measured in-situ, and to avoid street layout geometry, trees, and their leaf and other parameter effects that could influence comparison, an extensive data set needs to be gathered and analysed. Smart LED luminaires were installed in three city regions: one was a central area (higher traffic), and two were sub-urban areas (lower traffic); overall more than 1300 lighting poles were measured (Lux, Ra), and more than 100 luminaries were measured in dimmed regimes (P, W, Lux, Candela). To compare Dialux results with real in-situ measurements, 21-50 measurement points were obtained using lux 
meter. However, if we speak about large pilot sites with $>65$ streets ( $>1000$ luminaries), there would be too many measurements that would take a long time. Simplification was used as shown in Fig. 13a. In all places, lux values were taken in one measurement point in front of the pole and in the middle of the street. It must be noted that the street width and distances of poles were different and not constant even in the same street. Lighting pole (luminary mounting place) height and rotation and perpendicularity to the street of luminary were observed to have variations. The lighting system is a rather old heritage of the Soviet times, using poles (metal, concrete, wooden) and electrical cables of

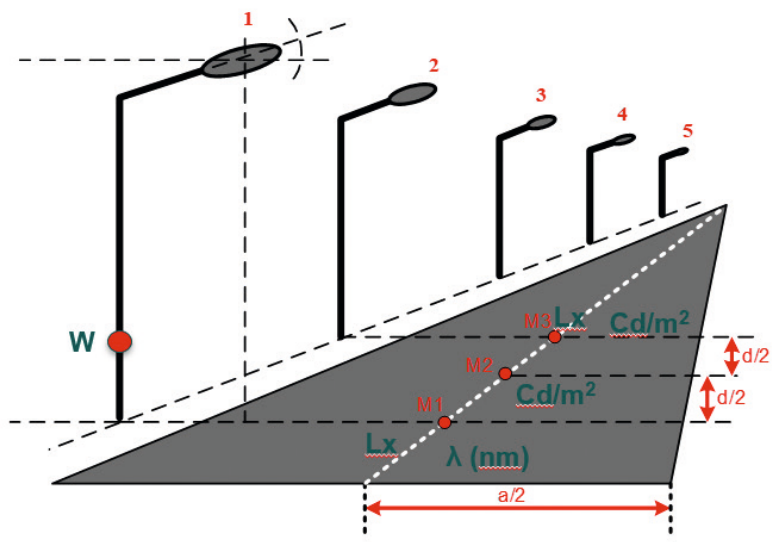

a) Measurement points of street profiles

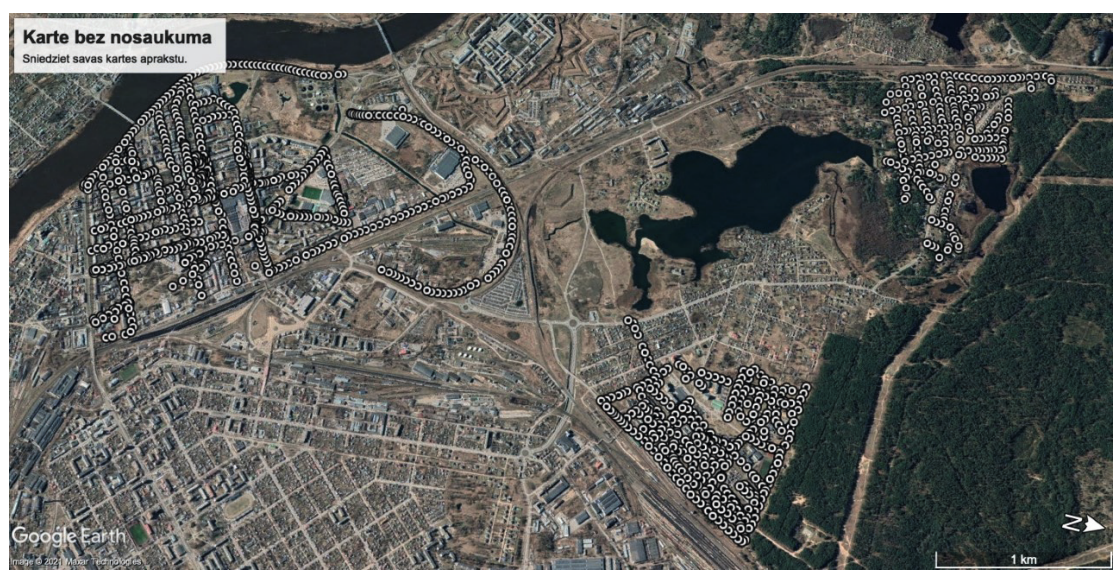

b) GPS coordinates of measurement points of large PilotSite

Figure 13. Large-scale street profile measurement plan (a) and GPS coordinates of the taken measurements 
different quality. Some repair works have been done, and new zinc-metal poles installed individually, or whole streets changed. The central part of the PilotSite had $33 \mathrm{ME3/ME4/ME5} \mathrm{class} \mathrm{streets,} \mathrm{and} \mathrm{the} \mathrm{urban} \mathrm{areas}$ had 19 streets each, ME4/ME5 and ME5/ME6, accordingly.

In-situ spectrum measurements were done using AvaSpec-2048USB2-UA (200-1200 nm) spectrometer for all PilotSite LED luminaries. From the measurements, AVANTES software allowed also calculating $C R I(R a)$ values from the obtained light spectrum. Thus we can see that $C R I(R a)$ values are in the range of 51-78. The CRI value in field measurements is affected by additional noise (Fig. 14b) and surrounding trees (Fig. 14c), which cover part of light creating. From Fig. 14a, we can see that the typical spectrum is at $442 \mathrm{~nm}$ and $580 \mathrm{~nm}$; thus, all luminaries were using the same quality LEDs, as all of them had the same spectrum maximum pikes (variation observed was 1-5\%) and colourimetric parameters. Candelas were measured using Konica Minolta LS-110, in two points (Fig. 13a), and in most cases showed values more than in Dialux calculations, at the same time keeping the uniformity parameters proportionally. Differences were related to the trees and their leaves, double-console (luminary) on pole, or different road surface type selected in Dialux.

Figure 15 shows samples of voltage and current waveform measurements in the pole (also including the control node and the movement detection sensor consumption), using Rohde \& Schwarz RTH1004 digital oscilloscope. For power parameter evaluation,
Ansis Avotins, Leslie Robert Adrian, Ricards Porins,

Peteris Apse-Apsitis, Leonids Ribickis

Smart City Street Lighting System Quality and Control Issues to Increase Energy Efficiency and Safety

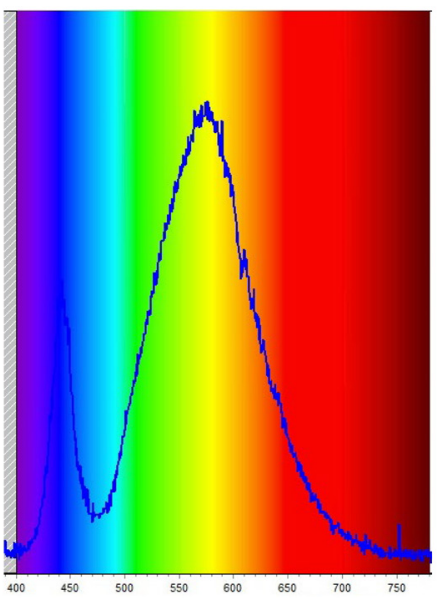

a) Normal spectrum

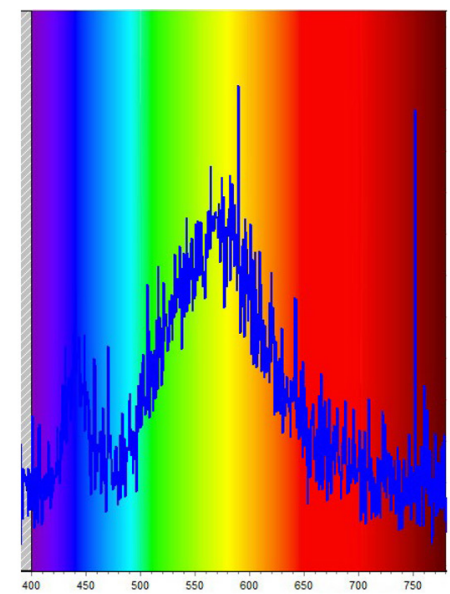

b) Indirect measurement / noise

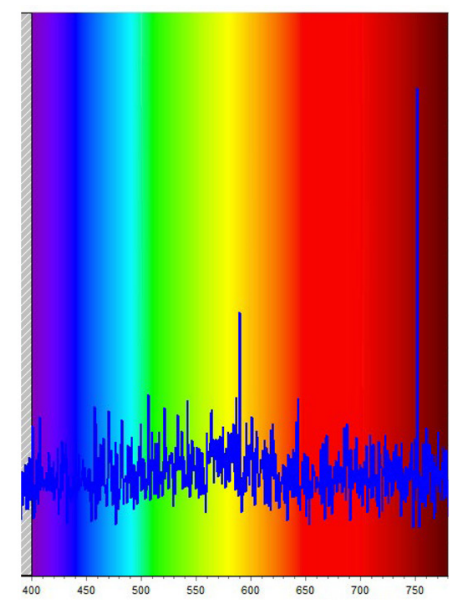

c) With great leave and noise impact

Figure 14. Typical samples of spectrum measurements 
a) Full power (100\%)
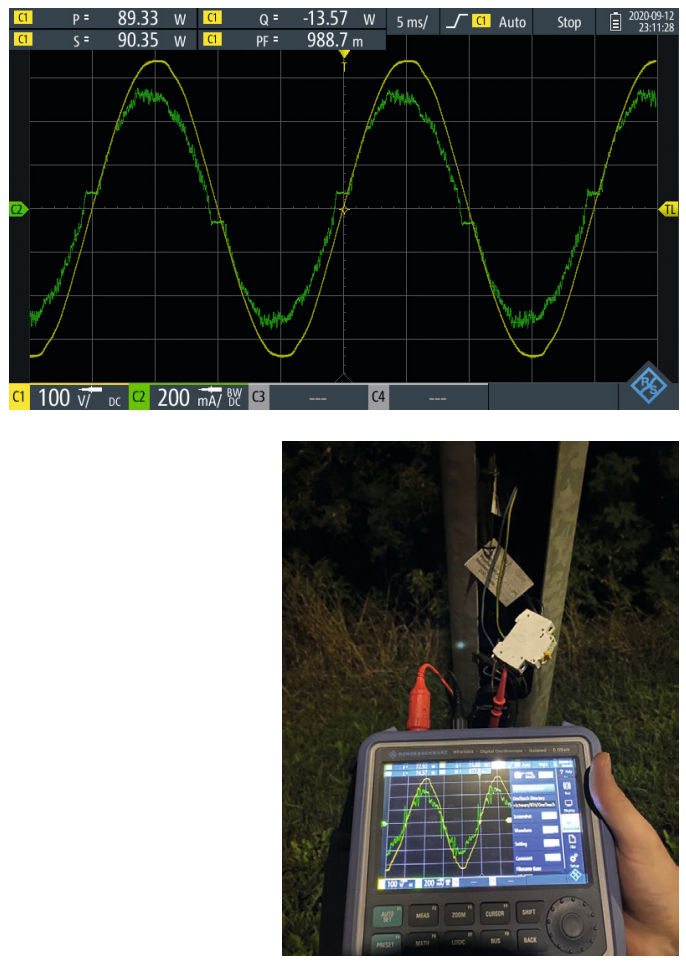

b) Dimmed to $40 \%$ of nominal power

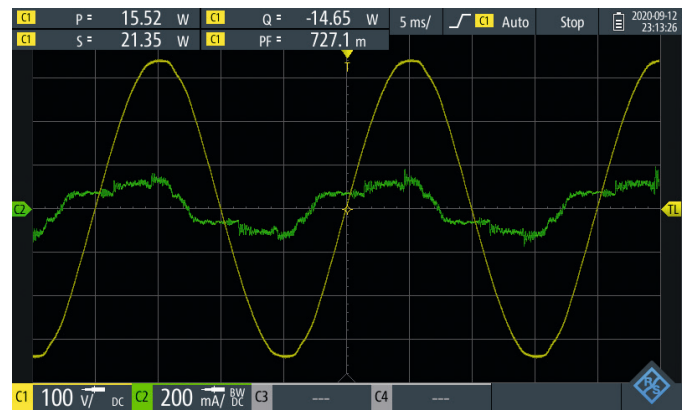

c) pole

Figure 15. A sample of power measurement waveforms of 86 W LED luminary

five measurements for each LED luminary (wattage nominal) were carried out using $20 \%$ dimming step. At the same time, illumination $E$, lux was measured under the luminary in the middle of the street. Dimming was done by sending to the radio signal-based control system the "dimming value" command using a system compatible segment controller. The particular street LED luminary (Fig. 15) is $86 \mathrm{~W}$ according to specifications; thus, the radio communication \& control node can be assumed to consume around $3.3 \mathrm{~W}$, as the measured power was $89.3 \mathrm{~W}$ at full power (light output also 100\%). The illumination E value was 20.7 lux. At the dimmed state of $20 \%$, the power consumption was $15.52 \mathrm{~W}$ and $E$ was 3.1 lux. The dimming was nonlinear; if we calculated the dimming, the power value at $20 \%$ should be $17.2 \mathrm{~W}$ and $E=4.14$ lux, or we could say that at $15.52 \mathrm{~W}$ it should be 3.59 lux. It means that in terms of light quality on the street, at the $20 \%$ level, we get $14 \%$ less, due to the "dimming regulation" algorithm implemented. However, this algorithm gives a better energy efficiency value ( $10 \%)$. Accurate and stable dimming profile (power and light output consistency) is a challenging task; also, the 
160

Light output should be constant

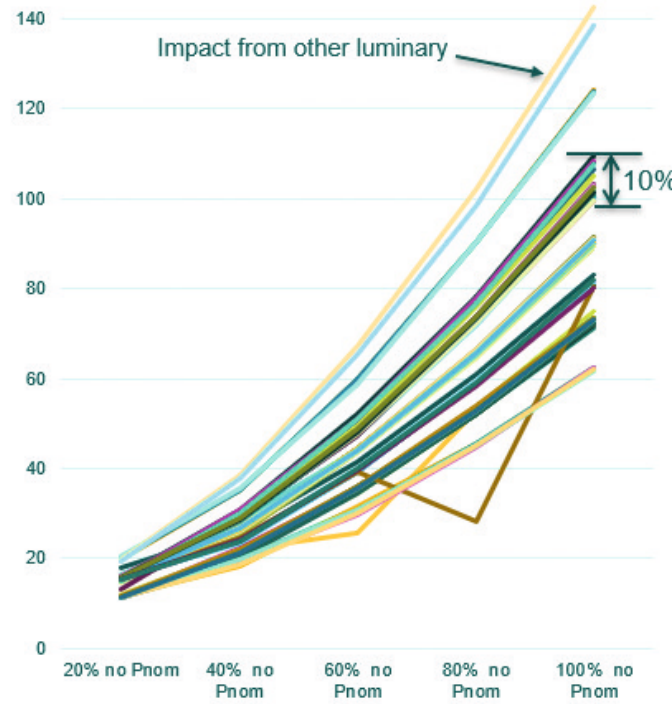

a)

c)

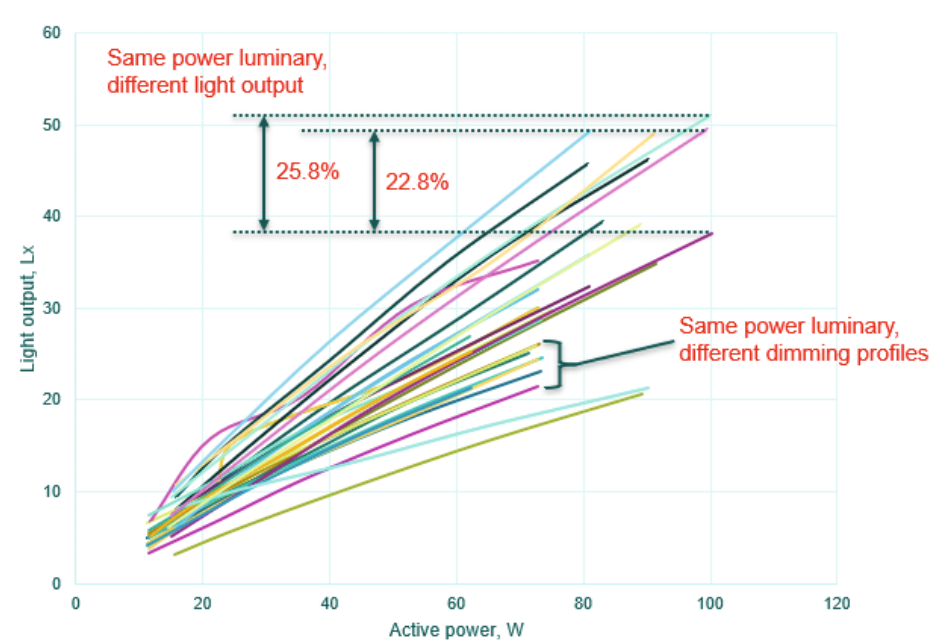

80

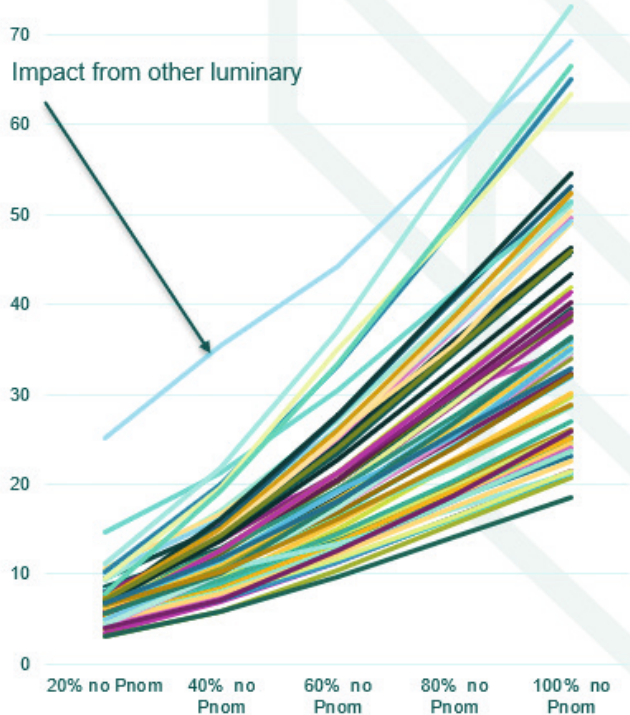

b)

Figure 16. Graphical relation of power consumption, dimming value and measured light output values

efficiency of LED driver in the dimmed stage decreases, which must be considered.

The dimming profile non-linearity can also be observed in Fig. 16, where Fig. 16a represents the consumed active power compared 
Table 7. Table 7. Measured $E$ (lux) value distribution min, average and max values from 717 measurement comparison per street

\begin{tabular}{|l|l|l|l|l|l|l|l|l|l|l|l|l|l|l|l|l|l|l|l|l|l|l|l|l|l|l|l|l|l|l|l|l|l|} 
MIN & 22 & 3 & 13 & 23 & 2 & 19 & 17 & 12 & 21 & 45 & 24 & 33 & 3 & 31 & 51 & 16 & 4 & 2 & 32 & 25 & 21 & 24 & 19 & 21 & 24 & 17 & 14 & 29 & 17 & 44 & 8 & 7 & 48 \\
\hline
\end{tabular}

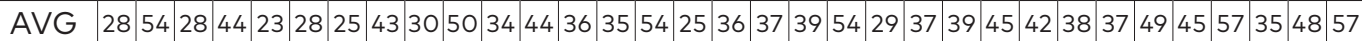

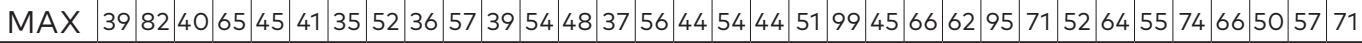

to dimming, Fig. 16b - measured light output (lux) compared to dimming command, and Fig. 16c - 30 luminary dimming profile measurements. The difference between the same luminary powers can be reached at $22.8-25.8 \%$, thus identifying the need for more proper calculation algorithms that include a street layout and potential power losses/consumption in the lighting pole.

A rather large difference between MIN, AVG and MAX values in measurements for real streets was obtained, as shown in Table 7. The extremely low values (minimums) of illumination level $E$ (lux) relate to the street trees. The trees were relatively high, and their foliage was very thick, thus covering the LED luminary and the emitted light to the road surface. It brings about problems in the city related to ensuring a balance of tree branch cuts and appropriate light amount; therefore,

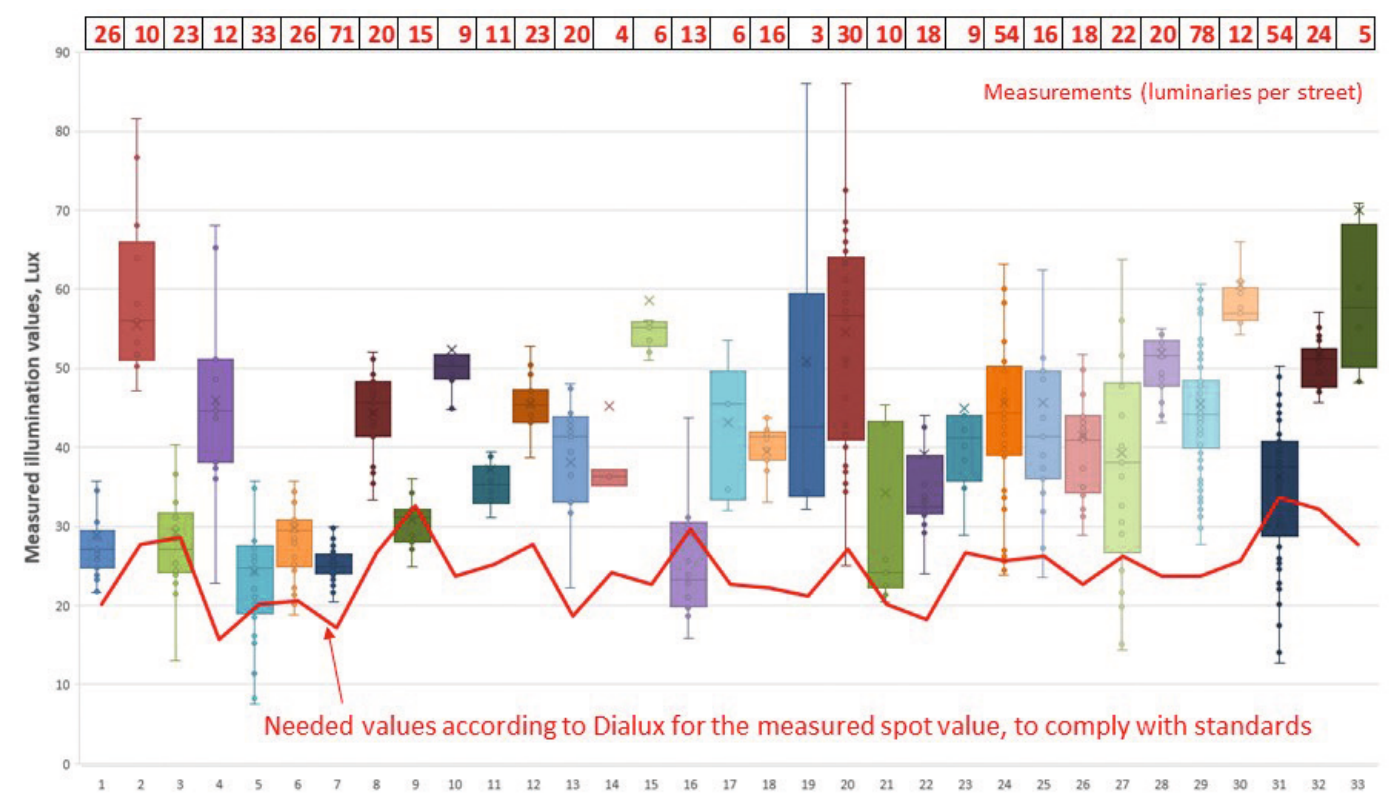

Figure 17. The measured illumination value distribution per street and needed minimums, according to Dialux 


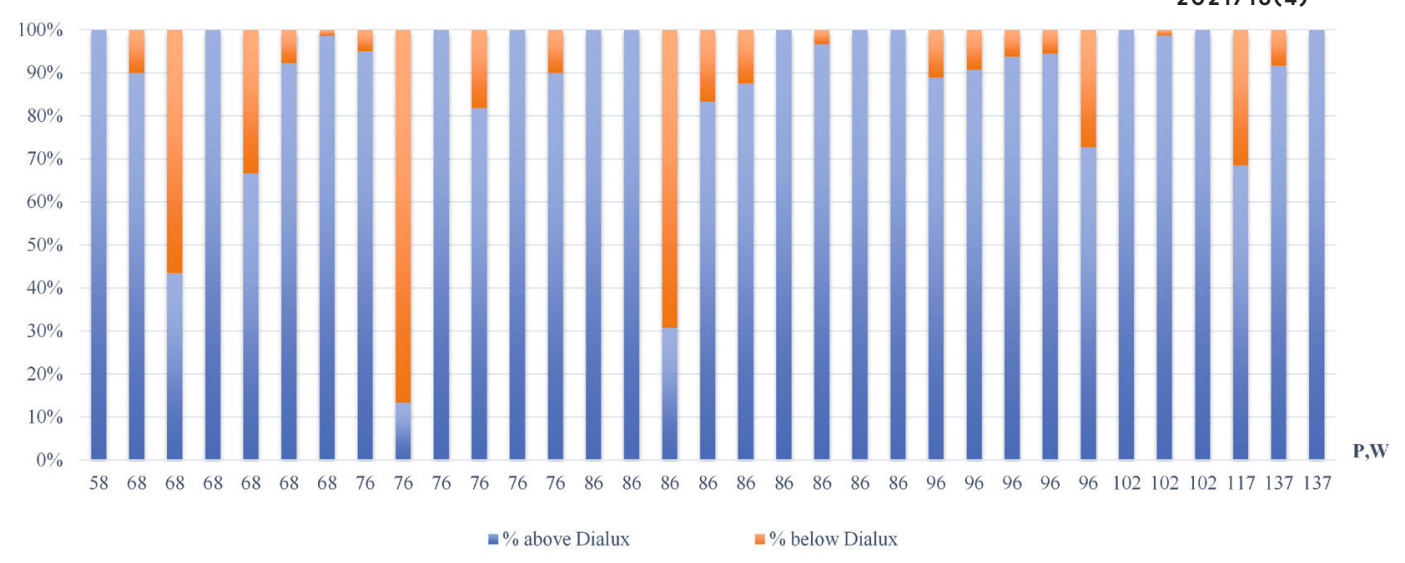

Figure 18. Measured value comparison with Dialux 4.13 obtained result values by luminary power type

professional arborist care must be provided in such places. Nevertheless, even for roads not affected by trees or other elements, the light deviation is still substantial. According to averaging the pole distances it was expected to have such an impact, but to get the difference in real lux values around $50 \%$ or even more, Dialux precision was around $10-15 \%$ for light distribution.

Figure 17 shows illumination level (lux) value distribution per street graphically. The red line represents the needed minimum value of Dialux calculation of the specific point of measurement to fulfil the $M$ class criteria. The red numbers above show measurement points (luminaries per street), the bars show the median analysis of all measurements (min to max), as well we can see how much light points are outside the median. The median (bar in the graph), could be treated as normal distribution according to the simulation results. There are many points above average or outside the median, which proves the quality and safety issues.

Suppose we want to consider numerically the measured values and red line (Dialux needed minimum to comply with $M$ class) in Fig. 17, then in Fig. 18 we can see the results, by how much \% we have more light (above) than needed in Dialux per luminary power type. We can exclude that particular luminary power affects this, but it is common to all types; thus, it is affected by street profile parameters and precision of the topographical measurements.

Light decrease potential per luminary power is given in Fig. 18, which is obtained by AVG measured values to reach minimum required ME Class illumination value for comparison with the measured spot 


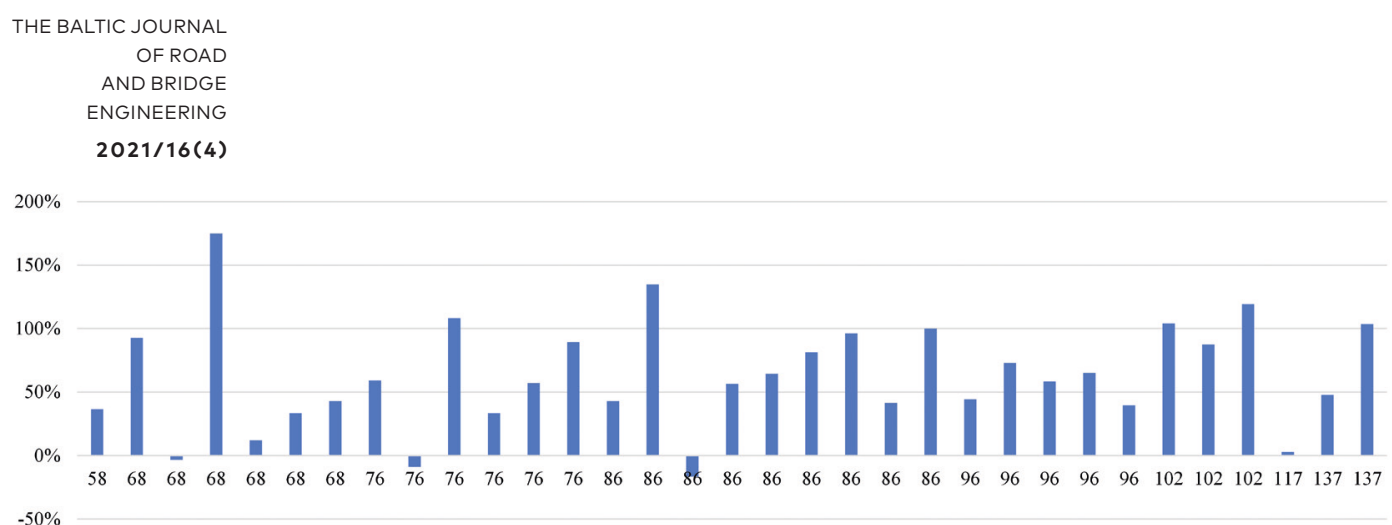

Figure 19. Light difference between Dialux and measured values by LED luminary power

value. The overall average potential is $63 \%$ reduction in terms of light during first years of LED luminary exploitation. This has happened because Dialux calculations use Maintenance Factor values of 0.85, 0.8, but in new installation, it is 1.00 , which could explain the difference of $15 \%$, but not of $63 \%$. It means that after the installation it is advisable to make comparative measurements, as extra savings can be obtained and safety could be improved, as too much light causes high Threshold Increment (glare) values, which was observed in most cases of candela measurements.

\section{Conclusions}

During last ten years, LED luminary total efficiency values increased from $50 \mathrm{Lm} / \mathrm{W}(6000 \mathrm{~K})$ in 2010 to $127 \mathrm{Lm} / \mathrm{W}$ in 2020 at $4000 \mathrm{~K}$. Lenses also improved to get better illumination uniformity values, as overall luminary quality was continuously improving.

Comparing Dialux simulation results with in-situ measurements, we can observe that in the period of 2009-2012 real light values were less than the simulated ones, but in the period of 2014-2020 we obtained higher values than the simulated ones. Too much light affects Threshold Increment and glare parameters, which can be dangerous to the traffic participants. In this case it also creates too much energy consumption and these are unnecessary costs for city/municipality; therefore, measurements after LED system installation should be mandatory, as the smart LED lighting systems can be adjusted properly, if needed. The average energy saving potential reaches $63 \%$ of nominal (maximum value programmed) power, at the same time fulfilling necessary road lighting quality and safety requirements. Simplifed lux measurement method can be applied to road lighting 
measurements, and uniformity can be validated by candela meter or by CCD type camera measurements.

Pole distance averaging, various street profiles and topographical parameters (CAD data) affect LED luminary selection before installation, but for an end-user it is better to have more light than needed instead of having less. Modelling precision could be improved if more accurate/variable street layouts could be created in simulation software.

LED ballast and control node regulation precision for a "dimming profile" algorithm can be improved, as it shows rather wide variations in the real illumination values on the street and can give $8-10 \%$ of energy savings.

\section{Funding}

The publication has been developed with the support of the European Regional Development Fund project "New Sensor and Control Algorithm Development for Smart City Street Lighting Systems (SAVAS)", under grant ggreement No. 1.1.1.1/18/A/115.

\section{REFERENCES}

Adrian, L. R. \& Ribickis, L. (2014). Intelligent power management device for street lighting control incorporating long range static and non-static hybrid infrared detection system. 16th European Conference on Power Electronics and Applications, Lappeenranta, 2014, pp. 1-5. https://doi.org/10.1109/EPE.2014.6911008

AIEE, (1935). The Important Rôle Played by Street Lighting in Automobile Fatalities. Transactions of the American Institute of Electrical Engineers, 54(9), 969-969. https://doi.org/10.1109/T-AIEE.1935.5057115.

Alam, M. Y., Anurag, H., Imam, M. S., Saha, S., Saha, M., Nandi, S., \& Chakraborty, S. (2020). Urban Safety as a Service During Bike Navigation: My Smartphone Can Monitor My Street-Lights. 2020 IEEE International Conference on Smart Computing (SMARTCOMP), Bologna, Italy, 2020. https://doi.org/10.1109/SMARTCOMP50058.2020.00035

Armas, J., \& Laugis, J. (2007). Increase pedestrian safety by critical crossroads: lighting measurements and analysis. 2007 European Conference on Power Electronics and Applications. https://doi.org/10.1109/EPE.2007.4417340

Avotins, A., Apse-Apsitis, P., Kunickis, M. \& Ribickis, L. (2014). Towards smart street LED lighting systems and preliminary energy saving results. 55th International Scientific Conference on Power and Electrical Engineering of Riga Technical University (RTUCON), Riga, 2014, pp. 130-135.

https://doi.org/10.1109/RTUCON.2014.6998219
Ansis Avotins, Leslie Robert Adrian, Ricards Porins, Peteris Apse-Apsitis, Leonids Ribickis

Smart City Street Lighting System Quality and Control Issues to Increase Energy Efficiency and Safety 
Avotins, A. \& Bicans, J. (2015). Context application to improve LED lighting control systems. 56th International Scientific Conference on Power and Electrical Engineering of Riga Technical University (RTUCON), Riga, 2015, pp. 1-4. https://doi.org/10.1109/RTUCON.2015.7343168

Bláha, Z., Sokanský, K. \& Novák, T. (2014). Solution of lighting for pedestrian crossing to increase their visibility. Proceedings of the 15th International Scientific Conference on Electric Power Engineering (EPE), Brno, 2014, pp. 637-640. https://doi.org/10.1109/EPE.2014.6839512

Cela, A., Natowicz, R. \& Abidi, S. (2019). Smart Street Lighting Energy Consumption Simulation. International Conference in Engineering Applications (ICEA), Sao Miguel, Portugal, 2019, pp. 1-5.

https://doi.org/10.1109/CEAP.2019.8883306

CEN/TR standards (2015-2016). EN13201 part 1 LVS CEN/TR 13201-1:2015 Road lighting - Part 1: Guidelines on selection of lighting classes. LVS EN 13201-2:2016 Road lighting - Part 2: Performance requirements. LVS EN 13201-3:2016 Road lighting - Part 3: Calculation of performance. LVS EN 13201-4:2016 Road lighting - Part 4: Methods of measuring lighting performance. LVS EN 13201-5:2016 Road lighting - Part 5: Energy performance indicators. Retrieved from https://www.lvs.lv/

Crabb, G. \& Crinson, L. (2008). The impact of street lighting on night-time road casualties. Transport Research Laboratory, 2008. https://www. semanticscholar.org/

Czyżewski, D. (2018). The Influence of Luminaire Photometric Data Accuracy on Road Lighting Calculations Quality. VII Lighting Conference of the Visegrad Countries (Lumen V4), Trebic, 2018, pp. 1-4. https://doi.org/10.1109/LUMENV.2018.8521163

Kuusik, M., Varjas, T. \& Rosin, A. (2016). Case study of smart city lighting system with motion detector and remote control. IEEE International Energy Conference (ENERGYCON), Leuven, 2016, pp. 1-5.

https://doi.org/10.1109/ENERGYCON.2016.7513906

LITES - Led-Based Intelligent sTreet lighting for Energy Saving. CIP Competitiveness and innovation framework programme (CIP)(2007-2013) project. https://cordis.europa.eu/project/id/238916

Mattoni, B., Burattini, C., Bisegna, F. \& Fotios, S. (2017). The pedestrian's perspective: How do illuminance variations affect reassurance. IEEE International Conference on Environment and Electrical Engineering and 2017 IEEE Industrial and Commercial Power Systems Europe (EEEIC/ I\&CPS Europe), Milan, 2017, pp. 1-5. https://doi.org/10.1109/EEEIC.2017.7977648

Maierová, L. (2018). Public Lighting, Public Health. VII. Lighting Conference of the Visegrad Countries (Lumen V4), Trebic, 2018, pp. 1-5. https://doi.org/10.1109/LUMENV.2018.8521032

Priyanka, S., Lakshmi, T. U. \& Sakthy, S. S. (2019). Web -Based Street Light System. 3rd International Conference on Computing and Communications Technologies (ICCCT), Chennai, India, 2019, pp. 159-162.

https://doi.org/10.1109/ICCCT2.2019.8824931 
Parise, G., Martirano, L. \& Mitolo, M. (2011). Electrical Safety of Street Light Systems. IEEE Transactions on Power Delivery, 26(3), 1952-1959. https://doi.org/10.1109/TPWRD.2011.2131690

Shlayan, N., Challapali, K., Cavalcanti, D., Oliveira, T. \& Yang, Y. (2018). A Novel Illuminance Control Strategy for Roadway Lighting Based on Greenshields Macroscopic Traffic Model. IEEE Photonics Journal, 10(1), 1-11, Art no. 8200211. https://doi.org/10.1109/JPHOT.2017.2782801

Siess, A., Hubel, K., Hepperle, D., Dronov, A., Hufnagel, C., Aktun, J. \& Wolfel, M. (2015). Hybrid City Lighting - Improving Pedestrians' Safety through Proactive Street Lighting. 2015 International Conference on Cyberworlds (CW), Visby, 2015, pp. 46-49. https://doi.org/10.1109/CW.2015.51

Yang, C., Nefedov, E., Sierla, S. \& Flikkema, P. (2015). Vehicle and pedestrian aware street lighting automation. IEEE 13th International Conference on Industrial Informatics (INDIN), Cambridge, 2015, pp. 1269-1274. https://doi.org/10.1109/INDIN.2015.7281917

Zanjani, P. N., Bahadori, M. \& Hashemi, M. (2013). Monitoring and remote sensing of the street lighting system using computer vision and image processing techniques for the purpose of mechanized blackouts (development phase). 22nd International Conference and Exhibition on Electricity Distribution (CIRED 2013), Stockholm, 2013, pp. 1-4.

https://doi.org/10.1049/cp.2013.1016
Peteris Apse-Apsitis, Leonids Ribickis

Smart City Street Lighting System Quality and Control Issues to Increase Energy Efficiency and Safety 